\title{
Un centinela para el monitoreo del cambio climático y su impacto sobre la biodiversidad en la cumbre austral de América: la nueva red de estudios a largo Plazo Cabo de Hornos
}

\author{
A sentinel for monitoring climate change and its impact on \\ biodiversity at the southern summit of the Americas: \\ the new Cape Horn Long-Term Socio-Ecological Research Network
} Ricardo Rozzi ${ }^{1,2,3,4}$, Ramiro D. Crego ${ }^{1,5}$, Tamara Contador ${ }^{1,6,7}$, Elke Schüttler ${ }^{1}$, Sebastián Rosenfeld ${ }^{1,8}$, Roy Mackenzie ${ }^{1}$, Omar Barroso ${ }^{1}$, Eduardo A. Silva-Rodríguez ${ }^{9}$, Ximena Álvarez-Bustos ${ }^{10}$, Alejandra Silva ${ }^{10}$, Irene Ramírez ${ }^{10}$, José Mella ${ }^{11}$, Jorge Herreros ${ }^{1,12}$, Javier Rendoll-Cárcamo ${ }^{1,7}$, Johanna Marambio ${ }^{1,9}$, Jaime Ojeda ${ }^{1,9}$, Felipe Méndez ${ }^{4,13}$,

Kelli P. Moses ${ }^{1}$, James Kennedy ${ }^{2}$, Shaun Russell ${ }^{1,14}$, Bernard Goffinet ${ }^{1,15}$, Leopoldo G. Sancho ${ }^{1,16}$, Flávio Berchez ${ }^{1,17}$, Brian Buma ${ }^{1,18}$, Francisco Aguirre ${ }^{1,19}$, Laura Sánchez-Jardón ${ }^{1,20}$, Eduardo Barros ${ }^{1}$, Rodrigo A.Vásquez ${ }^{1,21}$, Mary T. K. Arroyo ${ }^{3,21}$, Elie Poulin ${ }^{3,21}$, Francisco Squeo ${ }^{3,13}$, Juan J. Armesto ${ }^{3,4,22}$, Andrés Mansilla ${ }^{1,9}$ \& Francisca Massardo ${ }^{1,3}$

1 Programa de Conservación Biocultural Subantártica, Universidad de Magallanes, Parque Etnobotánico Omora, Puerto Williams, Chile.

https://orcid.org/0000-0001-5265-8726

$₫$ ricardo.rozzi@unt.edu

2 Sub-Antarctic Biocultural Conservation Program, Department of Philosophy and Religion -

Department of Biological Sciences,

University of North Texas, Denton, TX, USA.

3 Instituto de Ecología y Biodiversidad,

Santiago y Puerto Williams, Chile.

4 Cary Institute of Ecosystem Sciences,

Millbrook, New York.

5 Conservation Ecology Center,

National Zoological Park, Smithsonian Conservation Biology Institute, Front Royal, USA.

6 Laboratorio Wankara de Ecosistemas Dulceacuícolas Subantárticos y Antárticos, Instituto de Ecología y Biodiversidad y Universidad de Magallanes, Chile.

7 Núcleo Milenio de Salmónidos Invasores (INVASAL), Universidad de Concepción, Concepción, Chile.

8 Laboratorio de Ecosistemas Marinos Antárticos y Subantárticos (LEMAS), Universidad de Magallanes, Punta Arenas, Chile.

9 Instituto de Conservación, Biodiversidad y Territorio,
Facultad de Ciencias Forestales y Recursos Naturales, Universidad Austral de Chile, Chile.

10 Corporación Nacional Forestal, Región de Magallanes, Chile.

11 Alcaldía de Mar Islas Diego Ramírez, Isla Gonzalo, Armada de Chile.

12 División de Recursos Naturales y Biodiversidad, Ministerio del Medio Ambiente, Chile.

13 Departamento de Biología, Facultad de Ciencias, Universidad de La Serena, La Serena, Chile.

14 Tremborgh Botanical Garden, Bangor University, Wales, United Kingdom.

15 Department of Ecology and Evolutionary Biology, University of Connecticut, Storrs, CT 06269 USA

16 Departamento de Biología Vegetal II, Facultad de Farmacia, Universidad Complutense de Madrid, 28040 Madrid, España.

17 Departmento de Botánica, Instituto de Biociências, Universidade de São Paulo, São Paulo, Brasil.

18 Department of Integrative Biology, University of Colorado, Denver, CO, USA.

19 Instituto Antártico Chileno, Punta Arenas, Chile. 


\section{Resumen}

Las reservas de la biosfera tienen entre sus funciones apoyar la investigación científica, educación, capacitación y monitoreo. En la Reserva de la Biosfera Cabo de Hornos $(\mathrm{RBCH})$, creada el año 2005, estas funciones se han cumplido desde la conformación del Parque Etnobotánico Omora el año 2000 y con su implementación, el año 2008, como sitio co-fundador de la Red Chilena de Sitios de Estudios Socio-Ecológicos a Largo Plazo (LTSER-Chile). El año 2016, esta última se ha fortalecido con la creación de la Red de Sitios de Estudios Ecológicos a Largo Plazo Cabo de Hornos (LTER-Cabo de Hornos). Esta red incluye el Parque Omora y tres nuevos sitios que se agregan al monitoreo de la ecorregión subantártica de Magallanes. De sur a norte, los sitios son: (1) isla Gonzalo (56³1'S; 6843'O), extremo sur del archipiélago Diego Ramírez, con vegetación subantártica dominada por gramíneas y criptógamas, carente de especies leñosas; (2)

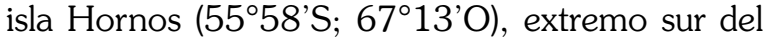
archipiélago Cabo de Hornos, que alberga los ecosistemas forestales más australes del planeta, dominados por coigüe de Magallanes (Nothofagus betuloides); (3) Parque Etnobotánico Omora (5457’S; 6740'O), isla Navarino, un sitio ideal para estudios sobre cambio climático y su impacto sobre la biota y ecosistemas subantárticos, puesto que protege una cuenca hidrográfica que incluye los tipos de hábitats característicos de la $\mathrm{RBCH}$ en un gradiente altitudinal con una disminución térmica análoga a la que ocurre con aumentos en latitud; y

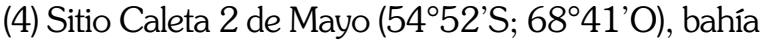
Yendegaia, en una zona ecotonal entre bosques siempreverdes y deciduos (producto del gradiente climático local), un sitio que será central para la futura conectividad entre Chile continental, Tierra del Fuego, isla Navarino y la $\mathrm{RBCH}$. El año 2015, UNESCO aprobó el Informe de la Primera Revisión Periódica de la $\mathrm{RBCH}$ que planteó la protección del archipiélago Diego Ramírez y creación del Parque Marino Islas Diego Ramírez-Paso Drake, objetivo que se logró con la promulgación de este nuevo parque el 2 de febrero de 2018 y su entrada en vigencia el 21 de enero de 2019 con la publicación del decreto de creación (Diario Oficial 2019). En este contexto, la nueva Red LTER-Cabo de Hornos adquiere una gran relevancia local, nacional $y$
20 Laboratorio Abierto de Ciencias Subantárticas, Centro Universitario Coyhaique, Universidad de Magallanes, Coyhaique, Chile.

21 Departamento de Ciencias Ecológicas,

Facultad de Ciencias, Universidad de Chile, Santiago, Chile.

22 Departamento de Ecología,

Pontificia Universidad Católica de Chile, Santiago, Chile.

global. A escala local, cubre una heterogeneidad ambiental representativa de la gran diversidad de paisajes y ecosistemas terrestres, dulceacuícolas y marinos de la $\mathrm{RBCH}$ y la ecorregión subantártica de Magallanes. A escala nacional, incorpora sitios subantárticos en el extremo austral de Sudamérica a la Red LTSER-Chile y a la Red de Monitoreo del Ministerio del Medio Ambiente. A escala global, los ecosistemas terrestres de la Red LTER-Cabo de Hornos sobresalen por dos razones principales: (a) estos ecosistemas subantárticos carecen de réplica en otros continentes del hemisferio sur y (b) los ecosistemas de latitudes altas son especialmente sensibles al cambio climático global. Así, la Red LTER-Cabo de Hornos contribuye a superar brechas geográficas críticas en la implementación de la Red Internacional de Estudios Ecológicos a Largo Plazo (ILTER). Para articular estos cuatro sitios y fortalecer la formación de capacidades técnicas y la transferencia de conocimientos a los tomadores de decisiones en el área de turismo de intereses especiales y otras actividades económicas sustentables, la Red LTERCabo de Hornos será administrada localmente desde el Centro Subantártico Cabo de Hornos (CESACH) que se inaugurará en Puerto Williams el año 2021. La implementación de la Red de Sitios LTER-Cabo de Hornos se ha basado en una estrecha colaboración con diversos actores públicos: Ministerio de Bienes Nacionales, Ministerio del Medio Ambiente, Corporación Nacional Forestal, Subsecretaría de Pesca y Acuicultura del Ministerio de Economía Fomento y Turismo, Dirección General de Aguas del Ministerio de Obras Públicas, Armada de Chile, Carabineros de Chile, Ilustre Municipalidad de Cabo de Hornos, Gobernación Provincial de la Antártica Chilena y Gobierno Regional de Magallanes y Antártica Chilena. En las siguientes fases, la Red de Sitios LTER-Cabo de Hornos y 
el CESACH fortalecerán la participación de la comunidad local, especialmente de la Comunidad Indígena Yagán de Bahía Mejillones, pescadores artesanales, operadores turísticos y la comunidad educativa, incluyendo actores privados. Ubicada en la "cumbre austral" de América, Puerto Williams, capital de la Provincia Antártica Chilena, podrá emerger como un polo mundial de investigación transdisciplinaria subantártica, equipada con un nuevo centro y red de estudios socio-ecológicos a largo plazo. La colaboración con actores regionales, nacionales e internacionales permitirá que la Red LTER-Cabo de Hornos y el CESACH: (i) aporten datos críticos, que abrirán nuevas oportunidades para el monitoreo del cambio climático y su impacto sobre la biodiversidad y ecosistemas en latitudes subantárticas; (ii) consoliden el monitoreo a largo plazo que constituye un componente esencial para diseñar de manera efectiva acciones de mitigación y adaptación; (iii) contribuyan a un modelo de desarrollo local sustentable que, asociado a la $\mathrm{RBCH}$, aporte desde el sur del mundo a un modelo de conservación biocultural que satisfaga las necesidades de bienestar socio-económico y sustentabilidad ambiental a múltiples escalas regionales y planetarias.

\section{Palabras clave:}

cambio climático, conservación biocultural, ecorregión subantártica de Magallanes, especies exóticas, reservas de la biosfera.

\section{Abstract}

Biosphere reserves have among their functions to support scientific research, education, training and monitoring. In the Cape Horn Biosphere Reserve $(\mathrm{RBCH})$, created in 2005 , this function has been fulfilled with the creation of the Omora Ethnobotanical Park in 2000, and its implementation in 2008 as a co-founder site of the Chilean Network of Studies Long-Term SocioEcological (LTSER-Chile). In 2016, this network has been strengthened with the addition of the new Cape Horn Long-Term Socio-Ecological Research Network (LTER-Cape Horn). The latter includes the Omora Ethnobotanical Park, and three new sites added to the monitoring of the sub-Antarctic Magellanic ecoregion. From south to north, the four sites are: (1) Gonzalo Island (56 $31^{\prime} \mathrm{S}$; $\left.68^{\circ} 43^{\prime} \mathrm{O}\right)$, at the southern end of the Diego Ramirez Archipelago, with subAntarctic vegetation dominated by grasses and cryptogams, devoid of woody species; (2) Horn

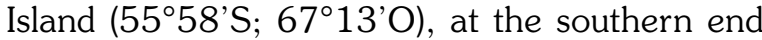
of the Cape Horn Archipelago, hosting the southernmost forest ecosystems on the planet, which are dominated by the evergreen beech (Nothofagus betuloides); (3) Omora Ethnobotanical Park (5457'S; 6740'O), Navarino Island, an ideal site for studies on climate change and its impact on biota and sub-Antarctic ecosystems, since it protects a watershed that includes a representative mosaic of characteristic habitats of the $\mathrm{RBCH}$ in an altitudinal gradient with a thermal decrease analogous to that which occurs with increases in latitude; and (4) Caleta 2 de Mayo Site (5452'S; $\left.68^{\circ} 41^{\prime} \mathrm{O}\right)$, Yendegaia Bay, in an ecotonal zone between evergreen and deciduous forests (product of the local climate gradient), at a site that will be central to future connectivity between Continental Chile, Tierra del Fuego, Navarino Island, and the $\mathrm{RBCH}$. In 2015, UNESCO approved the Report of the First Periodic Review of the $\mathrm{RBCH}$ that proposed the protection of the Diego Ramírez Archipelago and the creation of the Diego Ramirez Islands-Drake Passage Marine Park. This goal was achieved with the promulgation of this new park on February 2, 2018, and its entry into force on January 21, 2019 with the publication of the creation decree in the Diario Oficial of Chile. In this context, the new LTER-Cape Horn network acquires great local, national and global relevance. At the local scale, it covers a representative environmental heterogeneity of the great diversity of landscapes and terrestrial, freshwater and marine ecosystems of the $\mathrm{RBCH}$ and the sub-Antarctic Magellanic ecoregion. At the national scale, it incorporates sub-Antarctic sites, located at the southern end of South America, to LTSER-Chile and to the Monitoring Network of the Ministry of the Environment. On a global scale, the terrestrial ecosystems of the LTER-Cape Horn network stands out for two main reasons: (1) these sub-Antarctic ecosystems lack a geographical replicate in other continents of the southern hemisphere, and (2) high latitude ecosystems are especially sensitive to global climate change. Thus, the LTER-Cape Horn network helps to overcome critical geographical 
gaps in the implementation of the International Network for Long-Term Ecological Research (ILTER). In order to articulate these four sites and strengthen the training of technical capacities and knowledge transfer to decision makers in the area of special interest tourism and other sustainable economic activities, the LTER-Cape Horn network will be managed locally from the new Cape Horn Sub-Antarctic Center (Cape Horn Center) that will be inaugurated in Puerto Williams in 2021. The implementation of the LTER-Cape Horn network is based on a close collaboration with various public institutions: Ministry of National Assets, Ministry of the Environment, Subsecretary of Fisheries and Aquaculture of the Ministry of Economy Development and Tourism, National Forestry Service, General Water Directorate of the Ministry of Public Works, Navy of Chile, Chilean Police (Carabineros), Municipality of Cape Horn, Provincial Government of Chilean Antarctica, and the Regional Government of Magallanes and Chilean Antarctica. In the following phases, the LTER-Cape Horn network and the Cape Horn Center aim to strengthen the participation of the local community, especially the Yahgan Indigenous Community of Bahía Mejillones, artisanal fisheries, tour operators, and the educational community, including private actors. Located at the "southern summit" of the Americas, Puerto Williams, capital of the Chilean Antarctic Province emerges as a global hub for transdisciplinary sub-Antarctic research, equipped with a new center and the network of long-term socio-ecological studies. Collaboration with regional, national and international actors will allow the LTER-Cape Horn network and the Cape Horn Center to: (i) provide critical data, which will open up new opportunities for monitoring climate change and its impact on biodiversity and ecosystems in sub-Antarctic latitudes; (ii) consolidate long-term monitoring, which is an essential component to effectively design mitigation and adaptation actions; (iii) strengthen a local sustainable development model that, associated with the Cape Horn Biosphere Reserve, contributes from the south of the world, to a biocultural conservation model that meets the needs of socio-economic well-being and environmental sustainability at multiple regional and planetary scales.

\section{Key words:}

climate change, biocultural conservation, sub-Antarctic Magellanic ecoregion, exotic species, biosphere reserves.

\section{INTRODUCCIÓN}

La comuna Cabo de Hornos incluye los archipiélagos más australes del continente americano, que adquieren hoy un doble valor: (a) su carácter de refugio con un bajo grado de impacto humano directo sobre los ecosistemas y la biota subantártica, y (b) esta comuna se ubica en un punto sensible para el cambio climático, el extremo latitudinal sur del continente americano. En los ecosistemas de altas latitudes se registran algunas de las tasas de calentamiento más rápidas del planeta que gatillan cambios dramáticos en las biotas (Lawford et al. 1996; Körner, 2003; Hassan et al. 2005; Jägerbrand et al. 2009). Por esta razón se han impulsado estudios experimentales de las respuestas ecológicas de la biota terrestre subpolar al cambio climático, pero éstos se han concentrado en las zonas subárticas del hemisferio norte (Chapin et al. 1991; Lawler et al. 2006; Rozzi et al. 2012). Esto representa una brecha crítica en la cobertura planetaria del monitoreo del cambio global, puesto que los ecosistemas y biodiversidad terrestre, dulceacuícola y marina de Cabo de Hornos serían particularmente vulnerables debido a tres razones: (1) la forma cónica del sur de Sudamérica que culmina en punto con una superficie terrestre extremadamente reducida, (2) la carencia de otras masas terrestres en latitudes equivalentes en el hemisferio sur y (3) la separación de los archipiélagos de Cabo de Hornos por aproximadamente 1.000 kilómetros de Antártica hace que frente al calentamiento global la biodiversidad encuentre una barrera oceánica que puede ser infranqueable para un desplazamiento hacia latitudes más altas donde podrían mantener su nicho térmico subpolar (Rozzi, 2018; Buma et al. 2020). Como resultado de la investigación conducida por veinte años en el Parque Etnobotánico Omora, en el siglo XXI Cabo de Hornos ha sido identificado como la cumbre latitudinal austral del continente americano que representa un punto geográfico estratégico para el monitoreo del cambio global y su impacto sobre la biodiversidad subantártica (Rozzi, 2002; Rozzi et al. 2006a). 
Para contribuir al conocimiento y valoración de Cabo de Hornos como patrimonio natural subantártico y consolidarlo como un sitio centinela para monitoreo del cambio climático global, el año 1999 impulsamos el desarrollo de un programa de largo plazo de actividades de ciencia y educación (Rozzi et al. 2006b; Contador et al. 2015, 2018). En el año 2000, establecimos el Parque Etnobotánico Omora, en Puerto Williams, y el Programa de Conservación Biocultural Subantártica (Programa CBS) con el objetivo de vincular escalas locales, regionales, nacionales y globales en investigación, educación y conservación (Rozzi et al. 2010). Con el propósito de fortalecer nuestra propuesta, surgida en esta área remota, nos asociamos con instituciones académicas, de toma de decisiones medioambientales y servicios técnicos regionales, nacionales y contactamos al Programa $\mathrm{MaB}$ (del inglés Man and Biosphere; El Hombre y la Biosfera) de UNESCO, una iniciativa científica intergubernamental que procura mejorar la relación entre los seres humanos y el medio ambiente (Guevara \& Laborde, 2008; Karez et al. 2016).

Entre los años 2000 y 2005, en conjunto con la Corporación Nacional Forestal (CONAF) y la Gobernación de la Provincia Antártica Chilena, contribuimos a reactivar el Programa $\mathrm{MaB}$ en nuestro país y crear la primera reserva de la biosfera en Chile que integró la protección de ecosistemas marinos y terrestres: la Reserva de la Biosfera Cabo de Hornos (RBCH) (Rozzi et al. 2006b, 2007). El año 2015, asociado al Informe de la Primera Revisión Periódica de la $\mathrm{RBCH}$ y Respuesta del Programa MaB-UNESCO a este informe técnico sobre la primera década de esta reserva de la biosfera (Massardo et al. 2016), trabajamos junto a autoridades regionales y nacionales, comités de pesca con pescadores industriales y artesanales, equipos profesionales del

Ministerio del Medio Ambiente, Ministerio de Bienes Nacionales, la Corporación Nacional Forestal (CONAF), Subsecretaría de Pesca y Acuicultura del Ministerio de Economía Fomento y Turismo, Ministerio de Bienes Nacionales, Dirección General de Aguas del Ministerio de Obras Públicas, Armada de Chile, Carabineros de Chile, Ilustre Municipalidad de Cabo de Hornos, Gobernación Provincial de la Antártica Chilena y Gobierno Regional de Magallanes y Antártica Chilena para preparar el informe técnico que condujo a la creación del Parque Marino Islas Diego Ramírez-Paso Drake (Rozzi et al. 2017).

Los hechos asociados a la transición de la primera a la segunda década de la $\mathrm{RBCH}$ generan una nueva etapa en que se procurará integrar el Parque Marino Islas Diego Ramírez-Paso Drake con la $\mathrm{RBCH}$. El desafío central es implementar del mejor modo ambas áreas protegidas. Para este fin es necesario considerar que el Programa $\mathrm{MaB}$ integra la investigación, formación, supervisión y educación sobre la biodiversidad" (UNESCO, 1996, 2016). Esta misión se implementa a través de una red internacional de reservas de la biosfera que deben cumplir tres funciones complementarias, que se refuerzan mutuamente:

(1) apoyo logístico para investigación, promoviendo actividades de educación, capacitación y monitoreo,

(2) conservación de la biodiversidad, y

(3) desarrollo económico humano sustentable (UNESCO, 1996, Artículo 3, p. 17).

En este trabajo expondremos el enfoque que hemos desarrollado para satisfacer la primera de las tres funciones anteriores y para responder a la invitación hecha por el Consejo Internacional de Coordinación del Programa MAB a los Estados Miembros de la UNESCO en Lima, Perú, en el IV Congreso Mundial de Reservas de Biosfera del año 2016, a "utilizar las reservas de biosfera (respetando las políticas nacionales en materia de desarrollo sostenible) como sitios prioritarios u observatorios para la conservación de la biodiversidad y los ecosistemas, y para la investigación, el monitoreo, la educación, la atenuación y la adaptación al cambio climático" (UNESCO, 2016, p. 54).

Una innovación central para fortalecer esta función en la $\mathrm{RBCH}$ y el cumplimiento de esta nueva meta definida en el IV Congreso Mundial de Reservas de Biosfera el año 2016, fue complementar la visión del Programa $\mathrm{MaB}$ con la misión de la Red ILTER (del inglés International Long-Term Ecological Research Network; Red Internacional de Estudios Ecológicos a Largo Plazo). Para ello hemos trabajado con la Red Chilena de 
Sitios de Estudios Socio-Ecológicos a Largo Plazo (LTSER-Chile), adscrita a ILTER, y adaptado los cuatro objetivos centrales del plan estratégico de la Red ILTER (2006), los cuales son:

(a) fomentar la colaboración y la coordinación entre los científicos y sus redes de investigación a escala local, regional y mundial;

(b) mejorar la comparabilidad de los datos ecológicos a largo plazo entre sitios ILTER de todo el mundo, y facilitar su intercambio y preservación;

(c) distribuir información científica a investigadores, políticos y la ciudadanía para contribuir a desarrollar mejores prácticas de gestión de ecosistemas y toma de decisiones socio-ambientales en múltiples niveles; $y$

(d) facilitar la educación de futuras generaciones de científicos para comprender la dinámica de ecosistemas y la biosfera en el largo plazo.

Para implementar estos objetivos a escala local, regional y global hemos identificado dos brechas críticas:

(i) brechas geográficas en la cobertura de los sitios ILTER, que han omitido regiones australes del planeta (Rozzi et al. 2012);

(ii) brechas en los ámbitos de investigación que han sub-representado formas de conocimiento ecológico local y la cobertura de disciplinas, particularmente las humanidades, las artes y dimensiones filosóficas (epistemológicas y éticas) en la investigación socio-ecológica a largo plazo en todo el planeta (Rozzi et al. 2014, 2015).

Con el fin de contribuir a superar la primera de las brechas e implementar el apoyo logístico en investigación, promoviendo actividades de educación, capacitación y monitoreo en la $\mathrm{RBCH}$ y el nuevo Parque Marino Islas Diego RamírezPaso Drake, presentamos primero una síntesis y análisis de esta brecha geográfica, luego el plan de trabajo en investigación de la Red de Sitios de Estudios Ecológicos a Largo Plazo Cabo de Hornos (LTER-Cabo de Hornos) y una discusión de sus aportes para los ámbitos de educación y conservación. Respecto a la segunda brecha, hemos presentado un número especial en la revista Magallania (volumen 46, número 1) con múltiples artículos (e.g., Contador et al. 2018; Crego et al. 2018a; Lewis et al. 2018; Malebrán \& Rozzi, 2018; Méndez et al. 2018; Ojeda et al. 2018) que adoptan y transforman la aproximación metodológica de la filosofía ambiental de campo en la investigación, educación y conservación biocultural en sitios de estudios socio-ecológicos a largo plazo (Rozzi et al. 2015).

\section{BRECHAS DE COBERTURA GEOGRÁFICA EN EL MONITOREO ECOLÓGICO GLOBAL Y SUS CONSECUENCIAS}

Los estudios ecológicos y los observatorios ambientales han omitido, hasta ahora, algunas regiones de la Tierra que poseen atributos ecológicos críticos para el funcionamiento de la biosfera (Lawler et al. 2006). Posterior a la creación de la $\mathrm{RBCH}$ en el 2005, cuando analizamos la distribución de sitios de recopilación de datos de la mayor red mundial de monitoreo ecológico, ILTER, identificamos y nos propusimos contribuir a superar tres sesgos geográficos (Rozzi et al. 2012):

1) Concentración de sitios ILTER en el hemisferio norte. La Red ILTER incluye 733 sitios en 37 países, con 655 de ellos (89\%) en el hemisferio norte. Es lamentable que en el hemisferio sur, donde se encuentran las áreas de mayor diversidad biológica para muchos grupos de organismos, sólo existen 78 sitios (11\%) (Fig. 1). Este desbalance es un subproducto de la predominancia de tierras continentales y de la concentración de centros académicos y científicos activos en el hemisferio norte, particularmente en latitudes altas (Rozzi et al. 2012).

2) Dentro del hemisferio norte, los sitios de la Red ILTER se concentran en latitudes templadas y subpolares. Más de dos tercios de los sitios ( $\mathrm{n}=504 ; 69 \%$ ) de esta red internacional se ubican por sobre los $40^{\circ}$ de latitud norte. Llama la atención que sólo 31 sitios (menos del 4\%) de la Red ILTER se encuentran dentro del ámbito del bioma 


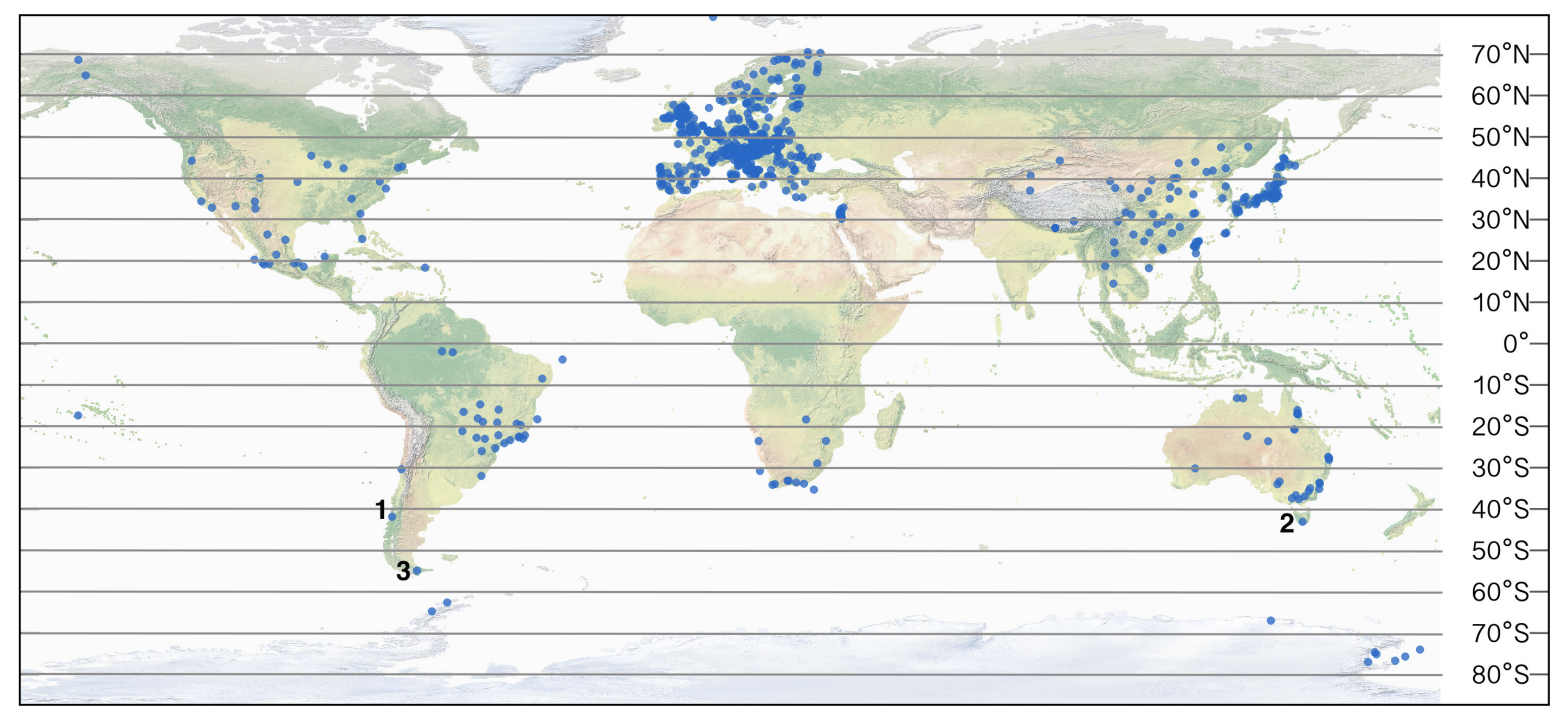

Fig. 1. Mapa de la distribución latitudinal de los sitios ILTER en el año 2017. Cada punto indica un sitio ILTER. Se señalan los tres sitios ubicados entre las latitudes 40 y 60ㅇ: (1) Estación Biológica Senda Darwin, (2) Warra Tall Eucalypt SuperSite,

Tasmania, y (3) Parque Etnobotánico Omora. Fuente de datos: https://data.lter-europe.net/deims.

tropical (entre las latitudes $20^{\circ} \mathrm{N}$ y $20^{\circ} \mathrm{S}$ ), donde se congrega gran parte de la diversidad de grupos de organismos a nivel mundial (Myers et al. 2000; Antonelli et al. 2018).

3) Ausencia absoluta de sitios ILTER entre los $50^{\circ} \mathrm{S}$ y $60^{\circ} \mathrm{S}$ (Fig. 1). En contraste con el hemisferio norte, hasta el año 2010, latitudes templadas y subpolares del hemisferio sur $\left(40^{\circ} \mathrm{S}\right.$ a $\left.60^{\circ} \mathrm{S}\right)$ sólo albergaban tres sitios de monitoreo que tenían el potencial de vincularse a la Red ILTER: (i) Estación Biológica Senda Darwin $\left(42^{\circ} \mathrm{S}\right)$, establecida en la Isla Grande de Chiloé, Chile, el año 1994; (ii) Warra Tall Eucalypt SuperSite $\left(43^{\circ} \mathrm{S}\right)$, establecido en Tasmania en 1995 como miembro de la Red Australiana de Sitios de Investigación de Ecosistemas Terrestres (Terrestrial Ecosystem Research Network, TERN, en la actualidad sin financiamiento, posiblemente inactiva); y (iii) Parque Etnobotánico Omora $\left(55^{\circ} \mathrm{S}\right)$, establecido el año 2000 en la isla Navarino, como sitio de investigación, educación y conservación de la RBCH (Fig. 1). Es relevante hacer notar que por razones geopolíticas en latitudes polares superiores a los $60^{\circ} \mathrm{S}$ (al sur de las latitudes subantárticas) y con menor accesibilidad, existen 10 sitios ILTER en la Antártica (Fig. 1).
La usencia de monitoreo ecológico a largo plazo en el ámbito latitudinal $40-60^{\circ} \mathrm{S}$ no se limita sólo a la Red ILTER. Por ejemplo, FLUXNET, una red global de torres micro-meteorológicas que miden los intercambios de $\mathrm{CO}_{2}$, vapor de agua y energía entre la biosfera y la atmósfera, opera de forma continua en los cinco continentes para registrar el flujo de $\mathrm{CO}_{2}$ en los ecosistemas terrestres. FLUXNET cuenta con 513 sitios en el hemisferio norte y sólo 21 sitios de monitoreo en el hemisferio sur, abarcando el ámbito latitudinal entre $70^{\circ} \mathrm{N}$ y $30^{\circ} \mathrm{S}$; por lo tanto, carece de sitios subantárticos (Sundareshwar et al. 2007). El año 2017, la Estación Biológica Senda Darwin se adscribió a FLUXNET incorporando un punto en la latitud $42^{\circ} \mathrm{S}$ (https://modis.ornl.gov/sites/?id=cl_ loslagos_senda_darwin_peatland). La Red Global de Observatorios Ecológicos de Lagos (Global Lake Ecological Observatory Network, GLEON) incluye 27 observatorios en los cinco continentes, pero estos sitios se concentran entre $69^{\circ} \mathrm{N}$ y $38^{\circ} \mathrm{S}$. GLEON omite el ámbito latitudinal $40-60^{\circ} \mathrm{S}$, pero incluye un observatorio lacustre en la Antártica a los $77^{\circ} \mathrm{S}$ (www.gleon.org). Los transectos terrestres establecidos por el Programa Internacional Geosfera-Biosfera (International GeosphereBiosphere Programme, IGBP) se encuentran en latitudes altas sólo en el hemisferio norte. En el hemisferio sur, estos transectos incluyen los biomas 
de bosque tropical húmedo, tropical semiárido y praderas ubicados en latitudes menores a los $40^{\circ} \mathrm{S}$ (Koch et al. 1995; Steffen et al. 1999), pero no incluyen puntos entre los 40 y $60^{\circ} \mathrm{S}$. Por lo tanto, el área geográfica de los bosques templados y subantárticos de América del Sur es un "punto ciego" en nuestra mirada científica del "cambio global" y está ausente de los programas más importantes de monitoreo del cambio ambiental global a largo plazo. Para abordar de manera comprensiva el estudio del cambio climático a escala global, se han identificado al menos cuatro razones por las cuales es crítico resolver la ausencia de monitoreo y estudios ecológicos a largo plazo en ecosistemas subantárticos del sudoeste de Sudamérica (Rozzi, 2018): (i) marcado contraste entre ecosistemas subantárticos y subárticos, (ii) región especialmente vulnerable al cambio climático, tal como las demás regiones subpolares, (iii) carece de réplica geográfica y posee atributos ecológicos y biogeográficos únicos, y (iv) en el siglo $\mathrm{XXI}$, la ecorregión subantártica del suroeste de Sudamérica conserva los ecosistemas terrestres, dulceacuícolas y marinos menos alterados del planeta.

\section{PASOS PARA SUPERAR EL VACÍO GEOGRÁFICO CRÍTICO EN EL MONITOREO ECOLÓGICO GLOBAL}

Con el fin de subsanar el vacío en el monitoreo global, el Programa CBS y el Instituto de Ecología y Biodiversidad (IEB-Chile) han logrado completar cuatro pasos secuenciales: (1) en el 2000, establecimos el Parque Etnobotánico Omora como un sitio de estudios ecológicos a largo plazo; (2) en el 2008, cofundamos la Red Chilena de Estudios Socio-Ecológicos a Largo Plazo (LTSER-Chile); (3) en el 2011, adscribimos formalmente la Red LTSER-Chile a la red internacional ILTER. Hoy concluimos con un cuarto paso, que constituye el cuerpo central de este artículo, el diseño $e$ implementación de la Red LTER-Cabo de Hornos, ampliada formalmente el 2015.

\section{Parque Omora: sitio LTSER}

El establecimiento del Parque Omora como sitio LTER comenzó a gestarse con su Programa de Estudios Ornitológicos a Largo Plazo iniciado en enero del año 2000 (Rozzi, 2002). El programa de anillamiento y recaptura de aves de bosque en el Parque Omora se ha mantenido ininterrumpido por seis días cada mes durante veinte años (20002020). El Programa de Estudios Ornitológicos a Largo Plazo del Parque Omora ha llegado a ser el programa continuo de estudios a largo plazo de aves de bosques templados y subantárticos más prolongado en el hemisferio sur, que está documentando diferencias marcadas con los patrones de migración y ecología de las aves migratorias de los bosques templados y boreales (Rozzi \& Jiménez, 2014; Quilodrán et al. en preparación).

En enero del año 2001 se iniciaron estudios de flora no-vascular que permitieron descubrir que Cabo de Hornos constituye un "hotspot" o centro de alta biodiversidad para briófitas (musgos y hepáticas) (Rozzi et al. 2008a; Goffinet et al. 2012). El año 2002 se incorporaron estudios marino-costeros que han demostrado una marcada estacionalidad en macroalgas subantárticas (Ojeda et al. 2014, 2019). El año 2008 se inició el programa de estudios de invertebrados dulceacuícolas, que ha descubierto diferencias importantes en las historias de vida de los insectos a lo largo de gradientes altitudinales y respecto a especies congenéricas en el hemisferio norte (Contador et al. 2012, 2014, 2015).

Las investigaciones se han realizado de manera integrada con programas de educación y capacitación en ecoturismo. Estos trabajos constituyeron el pilar fundamental para apoyar la propuesta que hiciéramos al Gobierno de la Región de Magallanes y Antártica Chilena y al Estado, para postular la creación de la $\mathrm{RBCH}$. La educación y la transferencia de los conocimientos, junto con una aproximación interdisciplinaria para integrar las ciencias, las artes y la ética ambiental se plasmaron en un enfoque centrado en la conservación biocultural (Rozzi et al. 2008b, c). Posteriormente este enfoque se ha extendido desde el Parque Omora para la creación e implementación de la Red LTSER-Chile.

\section{Creación de la Red LTSER-Chile}

El año 2008 se formalizó la Red LTSERChile en una reunión en el Parque Omora, su sitio 
más austral (Rozzi et al. 2010). La Red LTSERChile, coordinada y financiada en su primera etapa por el IEB, fue establecida con aportes de la Iniciativa Científica Milenio y la Comisión Nacional de Investigación Científica y Tecnológica (CONICYT), e incluyó tres sitios co-fundadores, con infraestructura y equipos de trabajo, que abarcan el gradiente latitudinal de los bosques de Chile desde su extremo norte hasta su extremo sur: Parque Nacional (PN) Bosque Fray Jorge (305, Gutiérrez et al. 2010), en la Reserva de la Biosfera Fray Jorge (Squeo \& Méndez, 2019), Estación Biológica Senda Darwin en Chiloé ( $42^{\circ} \mathrm{S}$, Carmona et al. 2010) y Parque Etnobotánico Omora $\left(55^{\circ} \mathrm{S}\right.$, Rozzi et al. 2010). A través de esta colaboración con la Red LTSER-Chile, los estudios de largo plazo realizados en el Parque Omora incorporaron los ecosistemas subantárticos altoandinos (Méndez et al. 2013), dulceacuícolas (Contador et al. 2015; Rendoll-Cárcamo et al. 2019; Simões et al. 2020) y fortalecieron estudios críticos sobre especies exóticas invasoras que representan una creciente amenaza para la biodiversidad en la $\mathrm{RBCH}$ (Rozzi et al. 2004; Schüttler et al. 2008, 2009, 2010, 2011, 2018, 2019; Rendoll-Cárcamo et al. 2016, 2017a, b; Crego et al. 2018b, c). La investigación socio-ecológica se fortaleció también con el trabajo desarrollado por el Programa de Postgrado en Ciencias y Conservación de la Universidad de Magallanes (UMAG), con apoyo de otras universidades y centros chilenos y extranjeros que han incluido el desarrollo de numerosas tesis de postgrado y cursos internacionales.

\section{Incorporación de la Red LTSER-Chile a la Red Mundial ILTER}

La Red LTSER-Chile se incorporó oficialmente a la Red ILTER en septiembre del año 2011 en el encuentro de coordinadores de sitios realizado en Japón. De esta manera, se incrementó el monitoreo ambiental a largo plazo en el vacío geográfico del ámbito latitudinal $40-60^{\circ} \mathrm{S}$ y resolvimos también la ausencia en la Red ILTER del bioma de los bosques templados de Sudamérica y la ecorregión subantártica de Magallanes (Rozzi et al. 2012). Los bosques templados y subantárticos se extienden a lo largo de una estrecha pero extensa franja continental en el sudoeste de Sudamérica, desde los $35^{\circ} \mathrm{S}$ hasta los $56^{\circ} \mathrm{S}$ en el Cabo de Hornos, zona que alberga los ecosistemas forestales más australes del mundo (Aravena et al. 2002; Rozzi, 2002). En contraste con los del hemisferio norte, los bosques templados sudamericanos han sido menos afectados por el impacto humano directo de los tiempos modernos (Armesto et al. 1998) y, por su ubicación geográfica, reciben las aguas de lluvia más limpias (sin contaminación) del planeta (Hedin et al. 1995; Weathers et al. 2000; Rozzi et al. 2012; Mach et al. 2017). Los metadatos de los sitios de estudio a largo plazo son incorporados actualmente en el repositorio de ILTER (Dynamic Ecological Information Management System-Site and Dataset Registry, DEIMS-SDR; https://data. lter-europe.net/deims/), donde están a disposición de la comunidad científica nacional e internacional.

La incorporación de la Red LTSER-Chile a la Red ILTER ha permitido iniciar estudios comparativos con otros sitios de la red global, considerando no sólo variables biofísicas (e.g., Djukic et al. 2018; Dornelas et al. 2018) sino también socio-ecológicas (Rozzi et al. 2015; Maass et al. 2016). En este último aspecto, con el fin de abordar tanto las brechas geográficas como interdisciplinarias en la Red ILTER, desde el Parque Omora hemos introducido una innovación para integrar las ciencias ecológicas y la ética ambiental tanto en la investigación como en los programas de educación y de asesoría en políticas públicas y toma de decisiones socio-ambientales. En la Red ILTER hemos liderado la creación de una nueva sección de educación y ética ambiental (Rozzi et al. 2014; Li et al. 2015; Maass et al. 2016), donde hemos incorporado una metodología innovadora desarrollada por el equipo del Parque Omora, la Filosofía Ambiental de Campo (Rozzi et al. 2010) que ha sido adaptada en otros sitios de las redes LTSERChile e ILTER (Aguirre, 2015; Holzer et al. 2018).

\section{NUEVA RED LTER-CABO DE HORNOS}

Para fortalecer el apoyo logístico al monitoreo durante la segunda década de la $\mathrm{RBCH}$, el año 2015 diseñamos la Red LTER-Cabo de Hornos. Esta nueva red de sitios de monitoreo y estudios ecológicos de largo plazo amplió la cobertura del Parque Omora, de la Red LTSER-Chile y de la red mundial ILTER, agregando tres nuevos sitios focales. Cada sitio 
comprende un conjunto de puntos de monitoreo. La suma de los puntos de monitoreo cubre una heterogeneidad ambiental representativa de la gran diversidad de paisajes de la $\mathrm{RBCH}$ y son los primeros sitios de estudio en el extremo más austral del continente americano. Esta área geográfica es extremadamente sensible al cambio climático global (y más ampliamente al cambio socio-ambiental global) y su localización permite monitorear sus impactos sobre la biodiversidad y el funcionamiento de los ecosistemas, incluyendo los servicios que brindan a la sociedad a escala local, nacional y global (Contador et al. 2015; Ojeda et al. 2019).

A escala global, los ecosistemas terrestres de la Red LTER-Cabo de Hornos sobresalen debido a la ausencia de réplicas latitudinales y biogeográficas (i.e., situaciones análogas) en otros continentes del hemisferio sur (Rozzi et al. 2012), por su alto estado de conservación (Rozzi et al. 2017) $y$ porque los ecosistemas de latitudes altas son especialmente sensibles al cambio global (Tuba et al. 2011). A escalas nacional y local, la Red LTERCabo de Hornos consolida una ampliación de los estudios iniciados por el equipo del Parque Omora $y$ aporta sub-red en el extremo austral de LTSERChile que: (a) consolidará la investigación sobre el impacto del cambio climático en los ecosistemas terrestres, dulceacuícolas y marinos en la $\mathrm{RBCH}$ y el Parque Marino Islas Diego Ramírez-Paso Drake, y (b) generará una nueva base de datos biofísicos en gradientes latitudinales y altitudinales escasamente conocidos, con marcados gradientes térmicos y cambios en biodiversidad (Contador et al. 2015). De sur a norte, la Red LTER-Cabo de Hornos incluye, además del Parque Omora, los siguientes tres nuevos sitios (Fig. 2):

(1) Sitio Isla Gonzalo (56³1'S; 68²4’O), extremo sur del archipiélago Diego Ramírez, con una vegetación subantártica dominada por gramíneas y criptógamas, carente de especies leñosas;

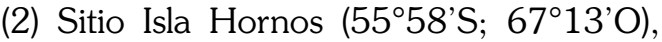
extremo sur del archipiélago Cabo de Hornos, que alberga los ecosistemas forestales más australes del planeta, dominados por coigüe de Magallanes (Nothofagus betuloides);

(3) Sitio Caleta 2 de Mayo (5452'S; $\left.68^{\circ} 41^{\prime} \mathrm{O}\right)$, bahía Yendegaia, en una zona ecotonal entre bosques siempreverdes y deciduos (producto del gradiente climático local), entre zonas "prístinas" que separan zonas con mayor impacto antrópico, hacia el oeste y hacia el este, respectivamente. Además, caleta 2 de Mayo será un punto nodal de conectividad entre Tierra del Fuego y el norte del país, como también con la isla Navarino y otros sitios, principalmente de interés turístico en la $\mathrm{RBCH}$ y eventualmente con la ciudad argentina de Ushuaia.

A continuación, caracterizamos concisamente los tres sitios complementarios de la Red LTER-Cabo de Hornos considerando: (a) aspectos administrativos, (b) biofísica general y clima, y diseño inicial del monitoreo y primeros resultados obtenidos en los (c) ecosistemas terrestres, (d) dulceacuícolas y (e) costero-marinos. Describimos en más detalle el Sitio Isla Gonzalo puesto que es la isla más austral de Sudamérica y ha asumido un papel central para la implementación del nuevo Parque Marino Islas Diego Ramírez-Paso Drake (Rozzi et al. 2017). El monitoreo de estos tres sitios se agrega al que hemos realizado durante dos décadas en el Parque Omora (54⒌'S), isla Navarino (Rozzi et al. 2010; Contador et al. 2015).

\section{Sitio Isla Gonzalo, archipiélago Diego Ramírez}

a) Caracterización administrativa. El año 1951, la Armada de Chile implementó una estación meteorológica en la pequeña isla Gonzalo que tiene un tamaño de 16,79 hectáreas (Fig. 3). Es la segunda en tamaño de las islas que conforman el archipiélago Diego Ramírez, cuyas islas tienen una superficie total de 79,17 ha. Desde el año 2007 este archipiélago constituye una Autodestinación con Fines de Conservación del Ministerio de Bienes Nacionales (Rozzi et al. 2017). Por esta razón, para implementar el Sitio Isla Gonzalo hemos suscrito convenios de colaboración con la Armada de Chile y el Ministerio de Bienes Nacionales (MBN), y además con el Ministerio del Medio Ambiente (MMA, que mantiene un programa de monitoreo ambiental a lo largo de Chile) y con la Subsecretaría de Pesca y Acuicultura (SUBPESCA) del Ministerio de Economía, Fomento y Turismo, que es responsable de la gestión del nuevo Parque Marino Islas Diego 

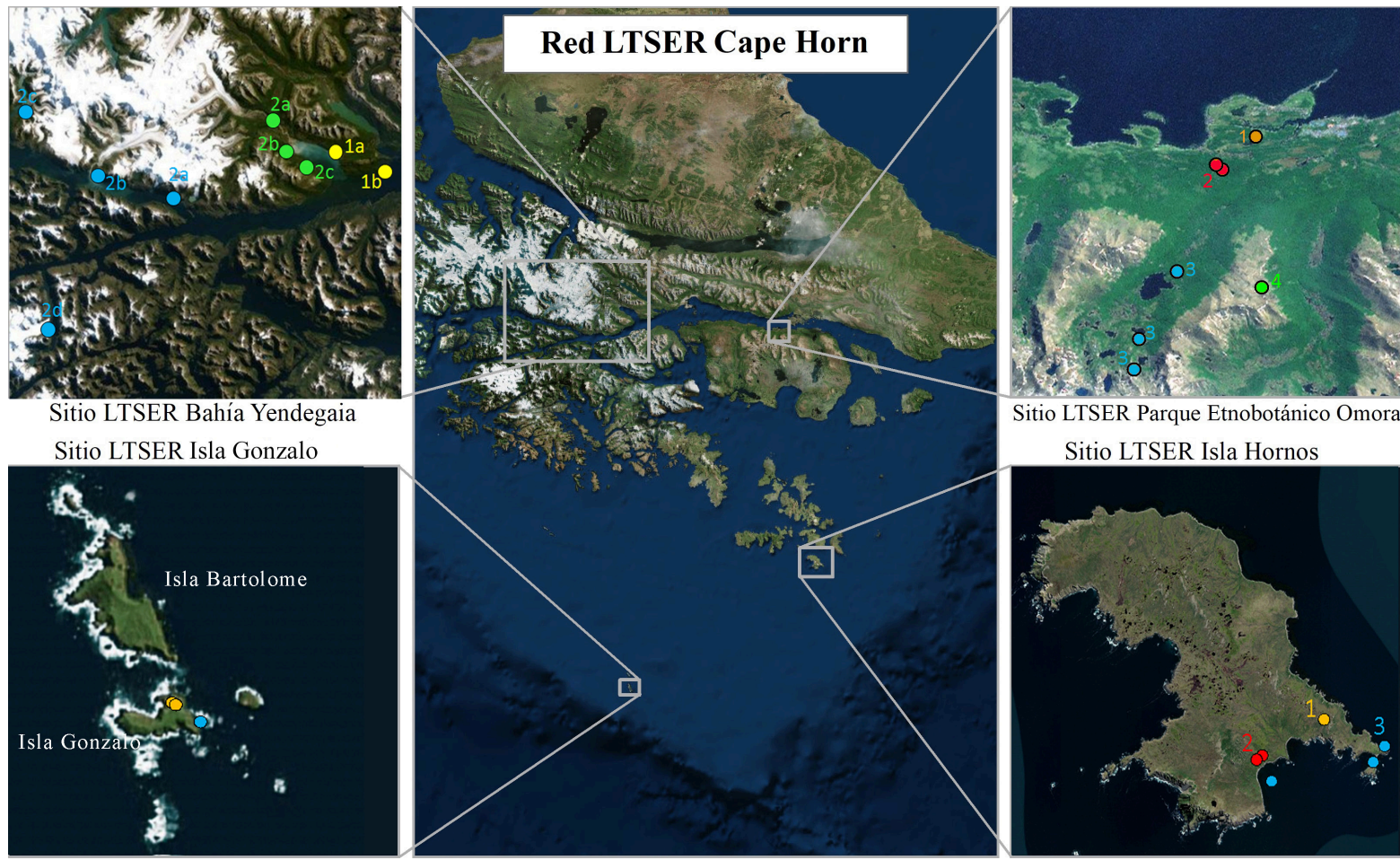

Sitio LTSER Parque Etnobotánico Omora Sitio LTSER Isla Hornos

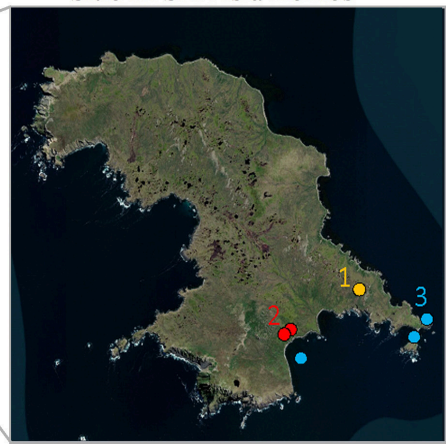

Fig. 2. Red LTER-Cabo de Hornos con sus cuatro sitios de estudios socio-ecológicos a largo plazo. La imagen central ilustra la ubicación de los cuatro sitios y sus puntos complementarios de monitoreo; nótese que el sitio del archipiélago Diego Ramírez está muy cercano al límite sur de la plataforma continental de Sudamérica. Los recuadros laterales amplifican cada sitio para indicar precisamente la ubicación de cada punto de monitoreo en ecosistemas terrestres, dulceacuícolas y costero-marinos. (A) Sitio Caleta 2 de Mayo, bahía Yendegaia, que incluye fuera de los parques nacionales (puntos amarillos) (1a) Estación Meteorológica y monitoreo Caleta 2 de Mayo, y (1b) parcelas vegetacionales adyacentes a Hito 26 en costa norte del canal Beagle; dentro del PN Yendegaia (puntos verdes), (2a) valle río Yendegaia, (2b) caleta Ferrari y (2c) caleta Contreras, y dentro del PN Alberto de Agostini (puntos azules), (2a) caleta Olla, (2b) glaciar Alemania, (2c) fiordo Pía y (2d) glaciar Fouque. (B) Sitio Parque Etnobotánico Omora, vecino a Puerto Williams en isla Navarino, que incluye (1) Estación meteorológica Lodge Lakutaia, (2) lugares de bosques canelo y notro de estudios de aves, (3) lugares de estudios de ecosistemas e invertebrados dulceacuícolas a lo largo del gradiente altitudinal del río Róbalo y (4) Estación meteorológica cerro Bandera. (C) Sitio Isla Gonzalo, archipiélago Diego Ramírez, ilustrando puntos de monitoreo terrestre (naranjo) y marino-costero (celeste). (D) Sitio Isla Hornos: (1) punto (amarillo) de estudios de aves en la península Espolón; (2) puntos (rojos) de estudios dulceacuícolas, parcelas permanentes de bosque y costero-marinos en la cuenca hidrográfica de exposición este del cerro Pirámide, y (3) puntos (celestes) de estudios marino-costeros.

Ramírez-Paso Drake. Desde diciembre de 2016, la información técnica sobre el sitio de estudio a largo plazo instalado en la isla Gonzalo se encuentra resguardada en el repositorio del sitio web DEIMS-SDR (https://deims.org/4480c35bbe50-4020-b272-6d0c5b9c21e9).

b) Caracterización biofísica y climática. La isla Gonzalo es parte del archipiélago Diego Ramírez y está asentada a una latitud de 56 31'30's; $68^{\circ} 43^{\prime} 00^{\prime \prime} O$, cercana al punto más austral de la plataforma continental de Sudamérica (Fig. 2). Poseen un clima oceánico, caracterizado por lluvias parejas todo el año y baja amplitud térmica anual. Durante nuestro primer año de registro, la temperatura promedio anual fue de $5,6^{\circ} \mathrm{C}$ y la precipitación anual de $1482,4 \mathrm{~mm}$; agosto fue el mes más frío $\left(3,3^{\circ} \mathrm{C}\right.$ temperatura promedio) y marzo el mes más cálido $\left(7,5^{\circ} \mathrm{C}\right)$ (Fig. 4). Las temperaturas promedio extremas mensuales (período 20132019) fueron $11,05^{\circ} \mathrm{C}$ en febrero $y-1,3^{\circ} \mathrm{C}$ en agosto. Las islas están expuestas a fuertes vientos con predominio del oeste, que el 2016 superaron los $100 \mathrm{~km} / \mathrm{h}$ en varios meses del año.

Respecto al equipamiento meteorológico, la Armada ha tomado desde la década de 1950 mediciones manuales basadas en la observación 

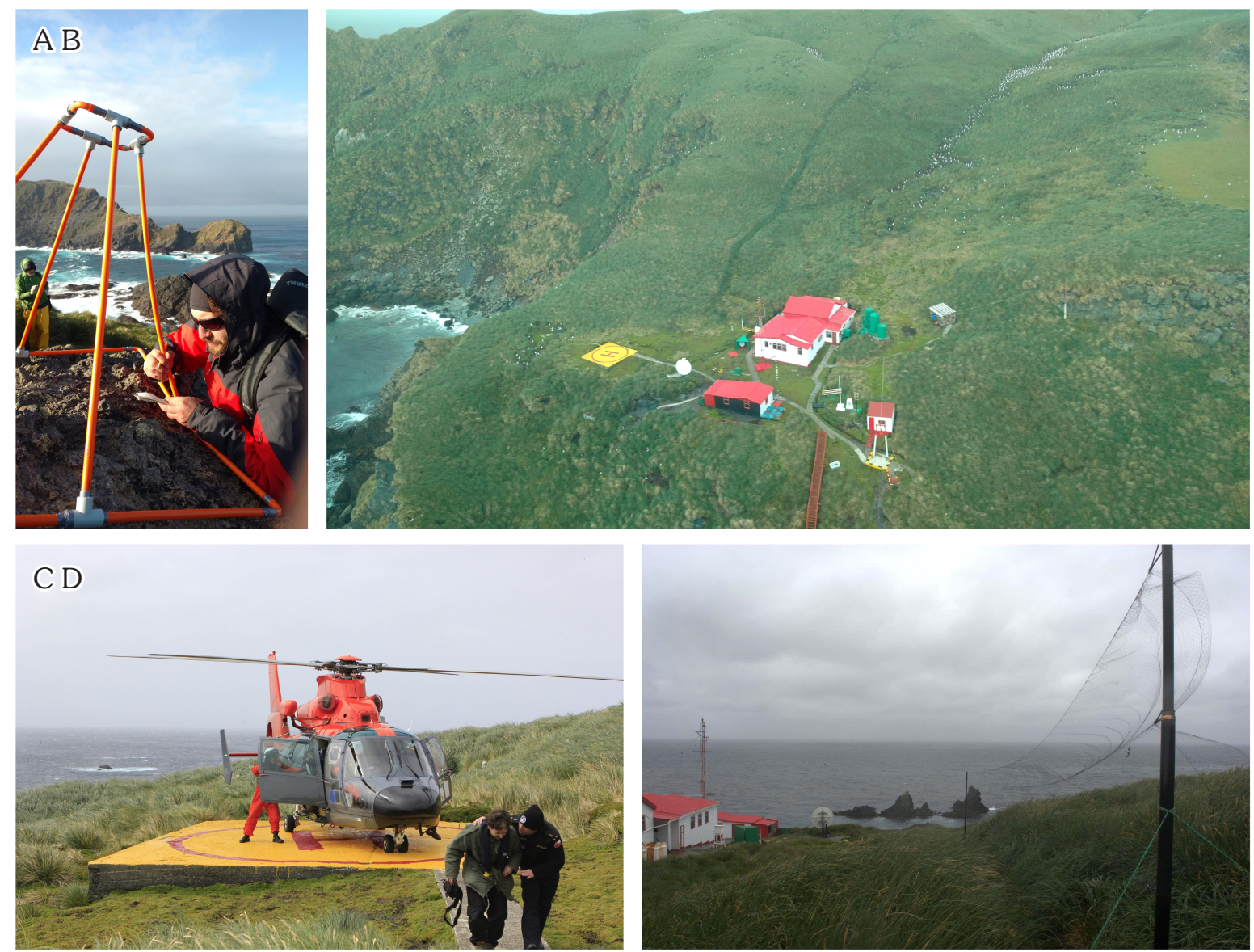

Fig. 3. Sitio Isla Gonzalo en el archipiélago Diego Ramírez, establecido en las cercanías del Faro Isla Gonzalo en colaboración con la Armada de Chile. A. El investigador Roy Mackenzie midiendo la cobertura de briófitas y líquenes en parcelas vegetacionales permanentes. B. Vista aérea de instalaciones de la Armada de Chile aledañas al sitio de monitoreo a largo plazo. C. Trabajo colaborativo entre personal de la Armada de Chile e investigadores para acceder al sitio de estudios. D. Redes para la captura y monitoreo de aves passeriformes instaladas en formaciones de pastos altos o tussock. Fotografías A, B y C: Roy Mackenzie; D: Omar Barroso.

permanente del personal a cargo. Sus registros se han realizado diariamente cada tres horas y han incluido observaciones semi-cuantitativas de (i) nubosidad y (ii) estado del mar (basado en la escala de Douglas, 1 a 10), mar de viento y mar de fondo, y mediciones cuantitativas de: (iii) velocidad y dirección del viento, (iv) temperatura del aire, incluyendo sistema de termómetros seco y húmedo, (v) humedad relativa, (vi) presión atmosférica y pluviometría (con totalizador graduado). Sus registros han sido digitalizados a mano $y$ posteriormente enviados directamente a Valparaíso. Con la ampliación de la Red LTER-Cabo de Hornos, el año 2021 en la isla Gonzalo se complementará la estación de la Armada con la instalación de una estación meteorológica con registro automático que mide en forma continua las siguientes variables: radiación solar, velocidad y dirección del viento, temperatura del aire, temperatura del suelo, humedad relativa del aire, humedad del suelo y pluviometría.

c) Ecosistemas terrestres. La isla Gonzalo se caracteriza por una vegetación que contrasta con los otros sitios de la Red LTER-Cabo de Hornos porque carece de especies arbóreas y todo tipo de plantas leñosas. La vegetación está dominada por densas formaciones de pastos altos (tipo (tussock) de Poa flabellata. Por esta razón, el archipiélago Diego Ramírez ha sido incluido dentro de la llamada biorregión gramino-turbosa subantártica (Pisano \& Schlatter, 1981). Los pastos alcanzan de 
1,5 a 2 m de altura, y generan un micro-hábitat protegido de los vientos fuertes (Pisano, 1972). La gran biomasa de pastos contribuye también a la formación de turba. Sobre suelos mal drenados la descomposición de la materia orgánica es lenta causando su acumulación. En noviembre de 2016 registramos puntualmente condiciones de suelo muy ácidas (pH 3.8) (Mackenzie et al. 2020, en este volumen), lo que contribuye a la acumulación de detritus orgánico y lentas tasas de descomposición.

Para algunos vertebrados (aves) $e$ invertebrados terrestres (e.g., coleópteros, dípteros, anfípodos y arácnidos) las comunidades de gramíneas proveen un hábitat clave. Por ejemplo, los albatros de ceja negra, Thalassarche melanophris (Temminck, 1828) y de cabeza gris, T. chrysostoma (Forster, 1785) presentan poblaciones de más de 10.000 parejas (Robertson et al. 2007, 2017), que utilizan la turba y los pastos para construir sus nidos en la época estival. En la isla Gonzalo proyectamos investigar los aportes que hacen los albatros, los pingüinos de penacho amarillo, Eudyptes chrysocome (Forster, 1781) y macaroni, E. chrysolophus (Brandt, 1837), y otras aves marinas que nidifican en el archipiélago Diego Ramírez, a los flujos de nutrientes del suelo (e.g., $\mathrm{N}, \mathrm{P}, \mathrm{K})$. Se identificarán los aportes desde los ecosistemas marinos a los terrestres mediante análisis biogeoquímicos y de isótopos.

Otra asociación vegetal presente corresponde a hierbas perennes en cojín dominadas por Plantago barbata G.Forst y Colobanthus quitensis (Kunth) Bartl. (Pisano \& Schlatter, 1981). Estas plantas se desarrollan sobre planicies con baja pendiente, donde forman un tapiz denso de baja altura junto a Cotula scariosa (Cass.) Franch. La flora vascular de la isla incluye sólo ocho especies (Pisano \& Schlatter, 1981; Mackenzie et al. 2020, en este volumen). En contraste, nuestros estudios en la isla Gonzalo han documentado, por primera vez, que la flora más diversa en el archipiélago Diego Ramírez está formada por briófitas (Goffinet et al. 2020, en este volumen).

Se han registrado más de 10 especies de hepáticas y musgos; los antocerotes, en cambio, parecen ausentes debido quizás a la carencia de bosques. Los musgos presentan un patrón de distribución notable, puesto que están ausentes del suelo bajo las formaciones de gramíneas altas, son escasos sobre la turba en áreas afectadas por el despeje de P. flabellata, y son comunes sobre rocas y suelos minerales descubiertos. La especie de musgo subantártico y halófito más típica es Orthotrichum crassifolium Hook.f. \& Wils. (más conocida bajo su nombre anterior

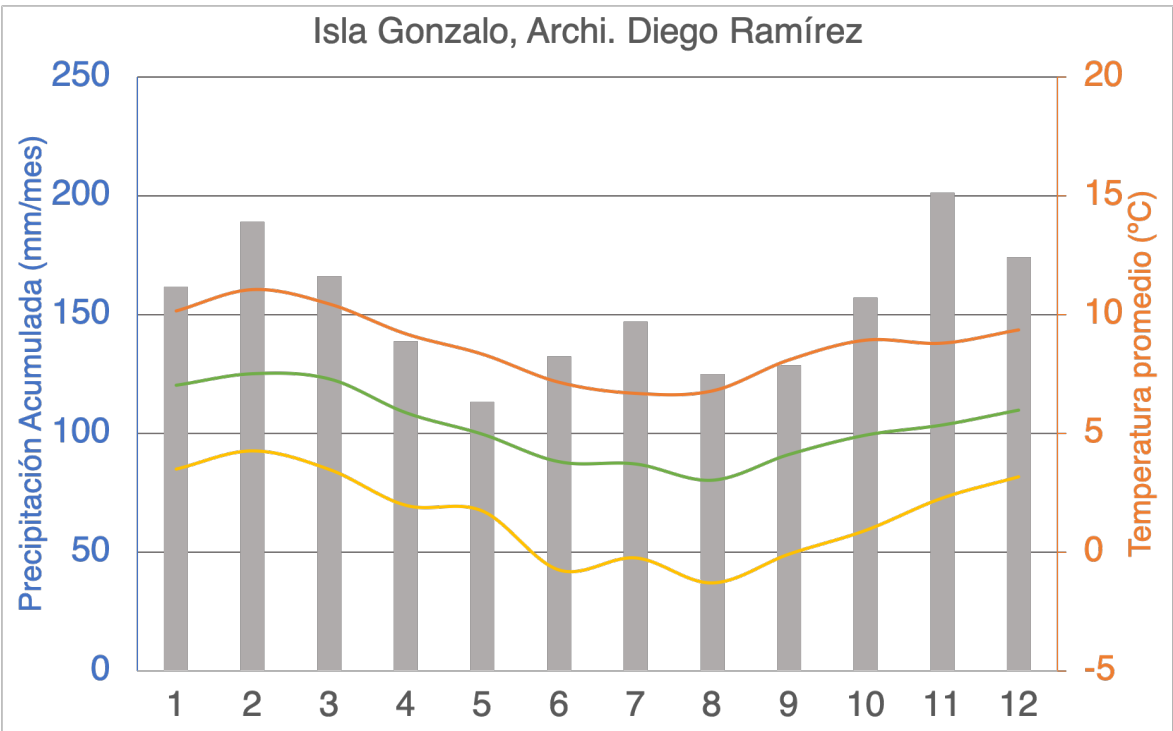

Fig. 4. Diagrama climático del Sitio Isla Gonzalo, archipiélago Diego Ramírez, basado en datos de temperatura media mensual (línea) y precipitación mensual (barras) calculados a partir de la base de datos meteorológicos de la Armada de Chile durante el año 2016. 
Muelleriella crassifolia), la que abunda sobre las rocas, por encima de la zona de marea hasta la zona más alta (50 $\mathrm{m}$ de altitud), donde los fuertes vientos mantienen una influencia de la salinidad sobre la vegetación (Fig. 5A, B). Otra especie de musgo común en la isla Gonzalo es Hennediella heimii (Hedw.) Zand., que crece sobre suelo mineral y asociada a la vegetación de tipo cojín (Fig. 5C, D). El musgo de tipo pleurocarpo más conspicuo registrado en la isla es Calyptrochaeta apiculata (Hook.f. \& Wils.) Vitt (Hookeriales), que crece en depresiones húmedas de vegetación perturbada por aves. Las hepáticas presentan un número de especies superior a los musgos, y crecen generalmente bajo los pastos altos, y en nidos abandonados de albatros. La hepática más común es Clasmatocolea vermicularis (Lehm.) Grolle (Goffinet et al. 2020, en este volumen).
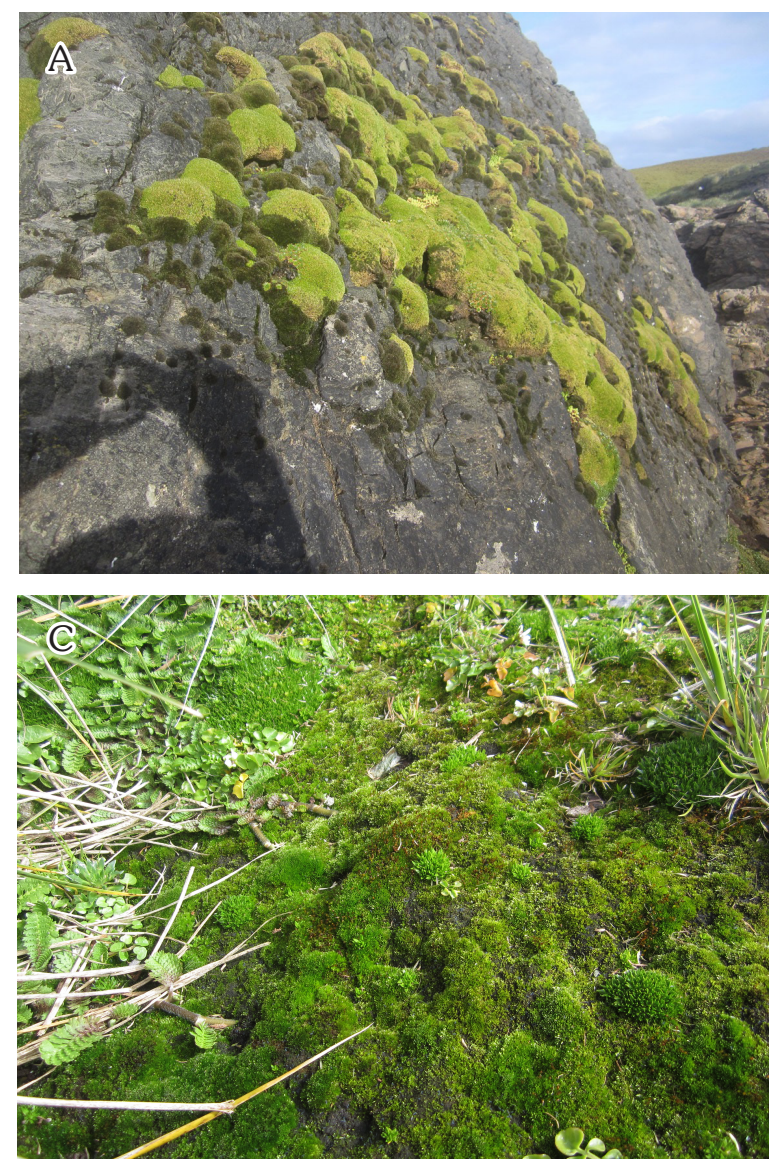

Estudio de vegetación. Para el monitoreo de las potenciales respuestas de la composición y cobertura de las especies vegetales al cambio climático, y más ampliamente al cambio global, hemos instalado una serie de parcelas de observación permanente. Para abarcar la heterogeneidad de formaciones vegetales, sobre una meseta de la isla Gonzalo que presenta un área homogénea de turbera de $P$. barbata limitada por las formaciones de tussock de $P$. flabellata, se diseñó un mosaico de 9 sets, con 9 cuadrantes cada uno. En cada set, los 9 cuadrantes de $1 \times 1 \mathrm{~m}$ se dispusieron de forma adjunta en grupos de $3 \times 3$. Dos sets (18 cuadrantes) se ubicaron sobre afloramientos rocosos (Fig. 6), donde prevalece la vegetación de briófitas dominadas por el musgo O. crassifolium. Un set (9 cuadrantes) se dispuso en el centro de la meseta de la isla Gonzalo donde se extiende un tapiz dominado por P. barbata
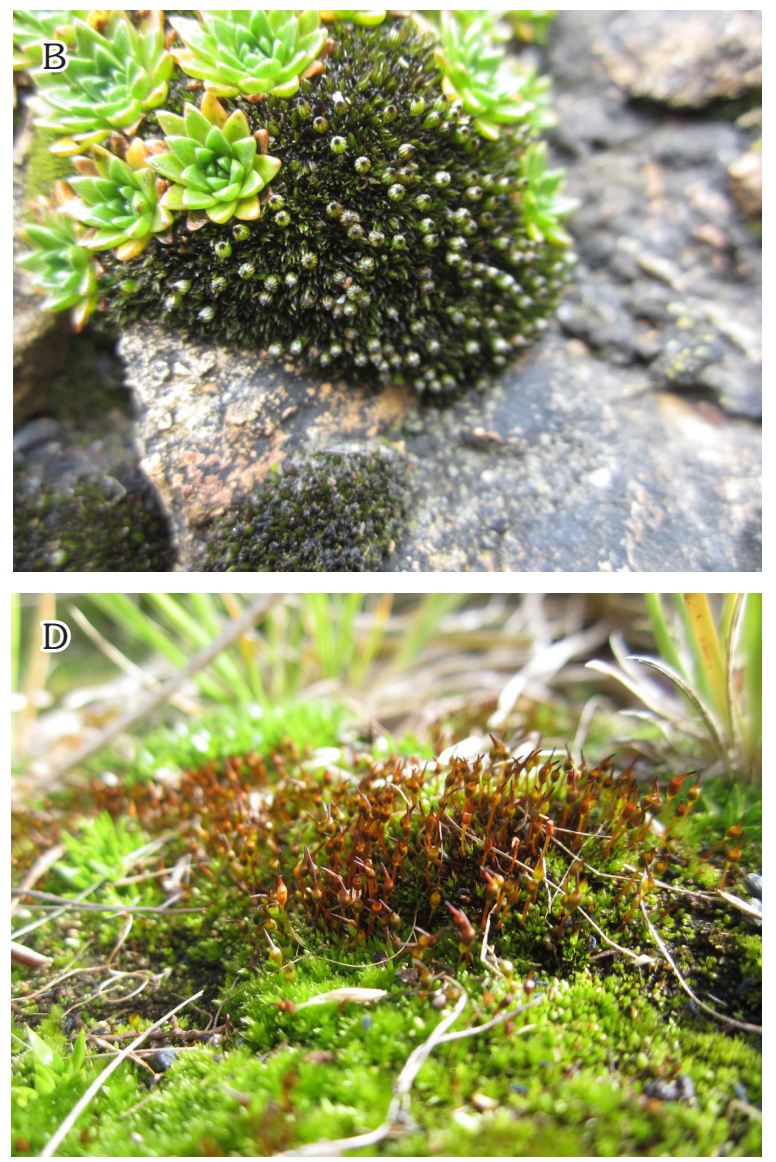

Fig. 5. Las dos especies de musgo más comunes en la isla Gonzalo. A y B: Orthotrichum crassifolium es abundante sobre rocas expuestas al spray marino que salpica hasta los $50 \mathrm{~m}$ de altitud. C y D: Hennediella heimii crece sobre la carpeta de plantas vasculares en zonas húmedas. Fotografías de Bernard Goffinet. 

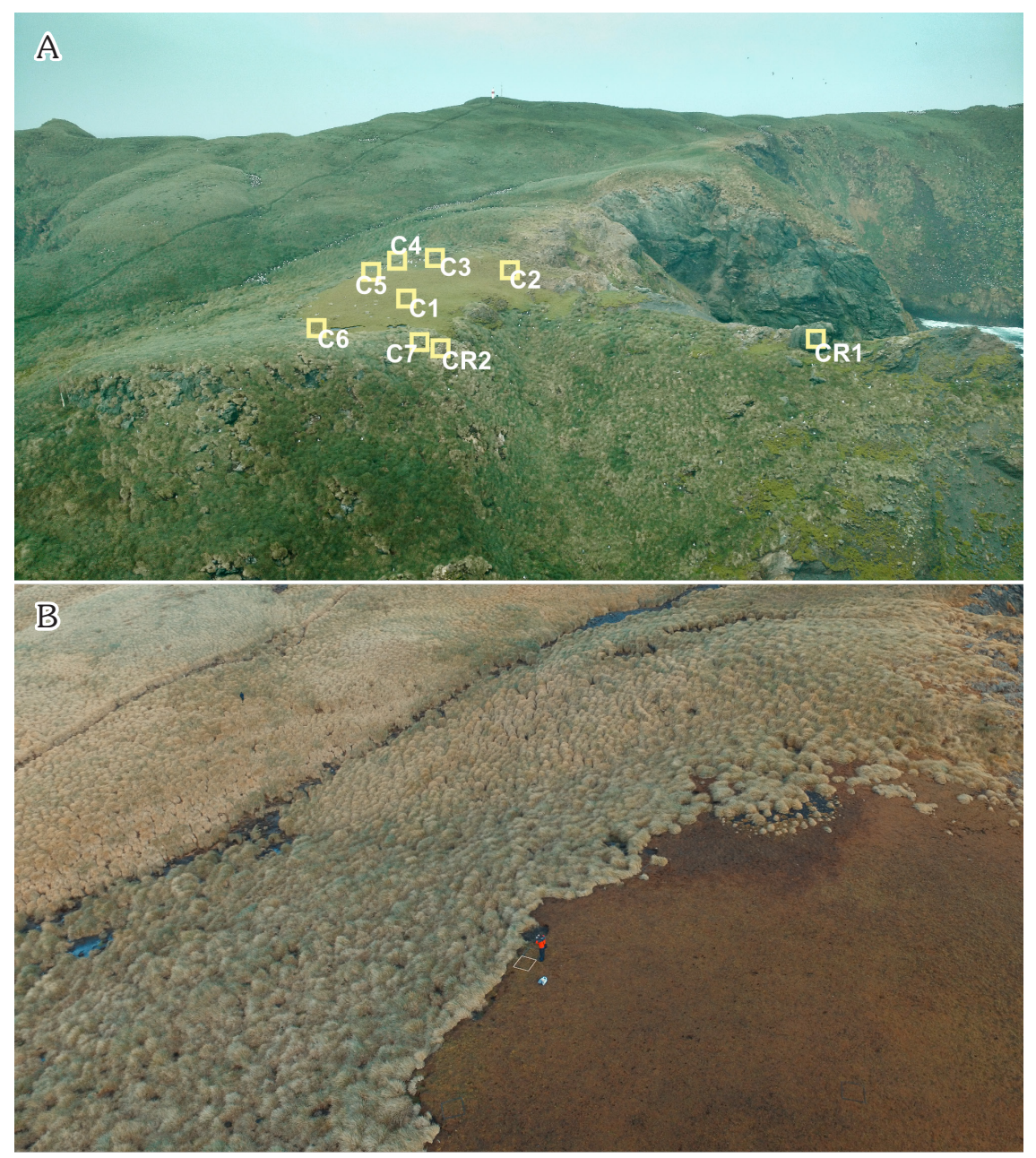

Fig. 6. Vista de la meseta y áreas aledañas donde se instalaron parcelas vegetacionales permanentes en la isla Gonzalo. Fotografías en la estación reproductiva (A, Noviembre 2016) y en la estación invernal (B, Julio 2017). Arriba se señala la ubicación de las 9 parcelas (cada una con 9 cuadrantes): CR1 y CR2 sobre sustrato rocoso, C1 sobre el tapiz tipo césped en el centro de la meseta, y C2-7 sobre ecotono entre el tapiz y formaciones de tussock. Abajo se ilustra un acercamiento a la parcela C4. Fotografías de Francisco Requena (arriba) y Roy Mackenzie (abajo).

y C. quitensis, y el musgo $H$. heimii. Seis sets (54 cuadrantes) se dispusieron en los bordes de este tapiz y formaciones de tussock de Poa flabellata en los sectores este, norte, oeste y sur de la meseta (Fig. 6A). Para registrar los cambios estacionales, en cada cuadrante hemos realizado dos registros fotográficos por año: uno en la estación reproductiva de las plantas (noviembre-febrero) y otro en la estación invernal (junio-agosto) (Fig. 6B).

Estudio de fauna. Se han realizado muestreos de vertebrados e invertebrados. Respecto a los vertebrados, los muestreos de aves combinan observaciones directas que generan listas de presencia de especies de aves avistadas en distintos tipos de hábitat, y un sitio permanente para captura y anillamiento de paseriformes con redes (de tipo redes de niebla, detalles en Rozzi \& Jiménez, 2014). Los muestreos consideran tres días en distintas épocas del año: en la estación reproductiva (noviembre-febrero), en invierno (junio-agosto) y otoño (abril-mayo). Las fechas de muestreo están sujetas a variaciones asociadas con el clima y el calendario de viajes de la Armada de Chile. En noviembre de 2016 se inició un estudio 
que por primera vez ha caracterizado la avifauna de Diego Ramírez durante todas las estaciones del año. Los estudios del primer ciclo anual han añadido nuevos registros en el sitio para nueve especies de aves (Barroso et al. 2020, en este volumen) y han determinado que tres especies terrestres son residentes todo el año: carancho negro Phalcoboenus australis (Gmelin, 1788), rayadito Aphrastura spinicauda (Gmelin, 1789) y churrete austral Cinclodes antarcticus maculirostris (Garnot, 1826).

A la fecha, no se han detectado mamíferos terrestres, nativos o introducidos, en el archipiélago Diego Ramírez. En noviembre de 2016 se investigó la presencia de roedores utilizando trampas Sherman dispuestas en distintos tipos de hábitat, incluyendo las inmediaciones de la casa y otras instalaciones de la Armada. Se instalaron 40 trampas a lo largo de dos transectos de $200 \mathrm{~m}$ cada uno, dispuestas cada 10 metros, durante 2 noches y 2 días. No hubo capturas ni registros indirectos de presencia de roedores. Se continuará con un esfuerzo dirigido a la detección temprana de especies de roedores invasoras, reconocidas mundialmente por sus efectos negativos sobre colonias reproductivas de aves. Tres especies de roedores (e.g., Rattus norvegicus Berkenhout, 1769, R. rattus Linnaeus, 1758, Mus musculus Linnaeus, 1758) han sido detectadas en otras islas subantárticas y podrían alcanzar el archipiélago Diego Ramírez, generando impactos negativos sobre la biota nativa, en particular sobre las aves (e.g., Jones et al. 2008).

Los estudios y muestreos de invertebrados terrestres se realizan en tres tipos de microhábitats: formaciones de tussock, tapiz de plantas en cojín y afloramientos rocosos. Los muestreos han abarcado dos estaciones del año (verano 2016, invierno 2017), utilizando trampas pitfall en los diferentes tipos de hábitat, y embudos de Berlese para contabilizar los invertebrados en distintos suelos (Contador et al. 2020, en este volumen). También se ha usado la recolección manual con aspirador para insectos voladores y con pinza para invertebrados ambulantes. Los invertebrados han sido conservados en etanol al 95\%. Inicialmente, se han identificado 32 taxa de invertebrados terrestres (Contador et al. 2020, en este volumen).
Una prioridad en los estudios de fauna terrestre en la isla Gonzalo corresponde al monitoreo y detección temprana del arribo de especies exóticas, tanto de vertebrados como invertebrados. La isla Gonzalo y las otras islas del archipiélago Diego Ramírez están libre de especies exóticas, pero la amenaza de invasión es inminente y es necesario estar alerta. En otras islas subantárticas, como las islas Georgias del Sur, Marion o Kerguelen, se han detectado no sólo vertebrados exóticos (e.g., roedores) sino también numerosos invertebrados, que incluyen colémbolos e insectos (Hänel et al. 1998; Lewis et al. 2005; Scott \& Kirkpatrick 2008; Lebouvier et al. 2011; Greenslade \& Convey, 2012).

d) Ecosistemas dulceacuicolas. En dos lagunas permanentes ubicadas a $110 \mathrm{~m}$ de altitud en la vecindad del Faro de la Armada, en noviembre de 2016 se instalaron data loggers (Hobo Onset® UA-002-08) dentro de cada laguna y a $10 \mathrm{~m}$ del borde de las lagunas para registrar la temperatura del agua y del aire a la altura del suelo. En cada laguna y en cada estación del año se han iniciado muestreos de invertebrados acuáticos utilizando redes " $\mathrm{D}$ ", obteniendo 5 muestras durante un período de 2 minutos, y se ha analizado la composición química del agua. Hasta el momento se han identificado solo 3 taxa de invertebrados dulceacuícolas, que incluyen un crustáceo y un arácnido del filo Arthropoda , y un verme del filo Annelda (Contador et al. 2020, en este volumen).

e) Ecosistemas costero-marinos. Las costas rocosas de la isla Gonzalo se caracterizan por su exposición al oleaje (Schlatter \& Riveros, 1997). Esto determina una exuberante abundancia y cobertura de Durvillaea antarctica (Chamisso) Hariot, que en costas expuestas alcanzan coberturas superiores a un 50\% (Marambio et al. 2020, en este volumen). El archipiélago Diego Ramírez representa el extremo sur de la distribución de los bosques submareales (o "kelps") compuestos por Macrocystis pyrifera (Linnaeus) C.Agardh y dos especies de Lessonia. Estos son los bosques de algas más australes del mundo. Se conservan en buen estado y proveen hábitat para una alta diversidad de organismos que encuentra en este ambiente zonas de refugio y reclutamiento (Mansilla et al. 2009; Rosenfeld et al. 2014). 
En la costa de la isla Gonzalo se establecieron 10 transectos permanentes para registrar la diversidad de comunidades bentónicas intermareales y submareales. Se consideraron tres niveles intermareales definidos mediante el protocolo descrito por Benedetti-Cecchi \& Cinelli (1997). Una vez definido los niveles (alto, medio y bajo) se dispusieron 10 transectos perpendiculares a la línea de costa, separados entre ellos por $25 \mathrm{~m}$ aproximadamente. A lo largo de cada transecto, para los niveles intermareales alto, medio y bajo, se dispuso un cuadrante al azar de 50x50cm (área de $2.500 \mathrm{~cm}^{2}$ ). La abundancia relativa de los taxa se ha estimado mediante el porcentaje de cobertura, usando la metodología de "puntos de contacto" (Murray et al. 2002), considerando 100 puntos de contacto distribuidos aleatoriamente en el cuadrante.

En los muestreos realizados hasta la fecha, se ha elevado el número de macroalgas conocidas para el archipiélago de 79 a 86 especies (Contreras et al. 1983; Mansilla \& Navarro, 2003; Marambio et al. 2020, en este volumen). Respecto a la fauna de invertebrados marinos, los muestreos de verano e invierno han registrado 51 especies de moluscos costeros, incluyendo 15 especies de micromoluscos, y permiten concluir también que la alta productividad de algas en el ambiente costeromarino sostiene una trama trófica compleja, con alta diversidad de herbivoros y carnivoros (Rosenfeld et al. 2020, en este volumen).

\section{Sitio Isla Hornos}

a) Caracterización administrativa. El Sitio Isla Hornos se ubica en el extremo sur del archipiélago Cabo de Hornos o de las islas Wollaston, cuyos ecosistemas terrestres y marinos están protegidos a través de la figura del PN Cabo de Hornos, creado el año 1945 con un área terrestre de 63.426 ha. El Decreto 995/1945 del Ministerio de Tierras y Colonización que creó este parque nacional menciona además las áreas marinas circundantes, indicando: "Créase el Parque Nacional Cabo de Hornos e islas adyacentes con el carácter de reserva de región virgen... comprendido dentro los siguientes deslindes: Norte, Golfo de Nassau; Este, con el océano Atlántico; Sur, con el océano Antártico; Oeste, con el Océano Pacífico y canal de Franklin" (Diario Oficial, 1945).
El año 1962 la Armada de Chile instaló un faro en la base del peñón de Cabo de Hornos o cerro Pirámide, y luego en 1992 construyó un segundo faro en la punta Espolón asociada a una Alcaldía de Mar (Fig. 7). Para implementar el plan de monitoreo, hemos suscrito convenios de colaboración con la Armada de Chile, el Ministerio del Medio Ambiente, la Subsecretaría de Pesca y Acuicultura y CONAF (Rozzi et al. 2017). Los estudios ecológicos en el PN Cabo de Hornos los iniciamos el año 2002 (incluyendo catastros de flora y fauna en todo el archipiélago, Rozzi et al. 2004, 2006b; Rozzi \& Jiménez, 2014), y los puntos de monitoreo permanente en Isla Hornos los fijamos en noviembre de 2016 en el sector aledaño a la Alcaldía de Mar y el cerro Pirámide (Fig. 2). Para implementar la colaboración inter-institucional, se ha iniciado un programa piloto de capacitación de personal de la Armada y transferencia de conocimiento científico para el turismo de intereses especiales (Fig. 7). La información técnica del Sitio Isla Hornos se encuentra disponible en el repositorio del sitio web DEIMS-SDR (https://deims.org/ fbe4066f-da38-49a0-95b7-6c22bac04f12).

b) Caracterización biofísica y climática. La isla Hornos alberga la cuenca forestada más austral del planeta, ubicada en la ladera de exposición este del cerro Pirámide (5558'27"S; 67¹6'13"O) que en su cara sur presenta el acantilado rocoso conocido como el Peñón del Cabo de Hornos (Fig. 7). La isla se ubica en la Provincia Biótica del Complejo de Tundra Magallánica (Pisano, 1977; Moore, 1983). Los bosques siempreverdes de coigüe de Magallanes (Nothofagus betuloides (Mirb.) Oerst.) prevalecen sólo en las laderas protegidas del viento (Rozzi et al. 2006b). La precipitación promedio es de $1.357 \mathrm{~mm}$ anuales y la temperatura media anual es $5,2^{\circ} \mathrm{C}$ (Pisano, 1980a).

Respecto al equipamiento meteorológico, desde la década de 1960, la Armada de Chile ha tomado mediciones manuales, discretas, basadas en la observación permanente del personal a cargo en la isla Hornos, península Espolón. Sus registros se han realizado diariamente cada tres horas y han incluido tanto observaciones semi-cuantitativas como mediciones cuantitativas. Las primeras incluyen nubosidad y estado del mar (basado en la escala de Douglas, 1 a 10), mar de viento y mar de fondo. Las mediciones cuantitativas incluyen 

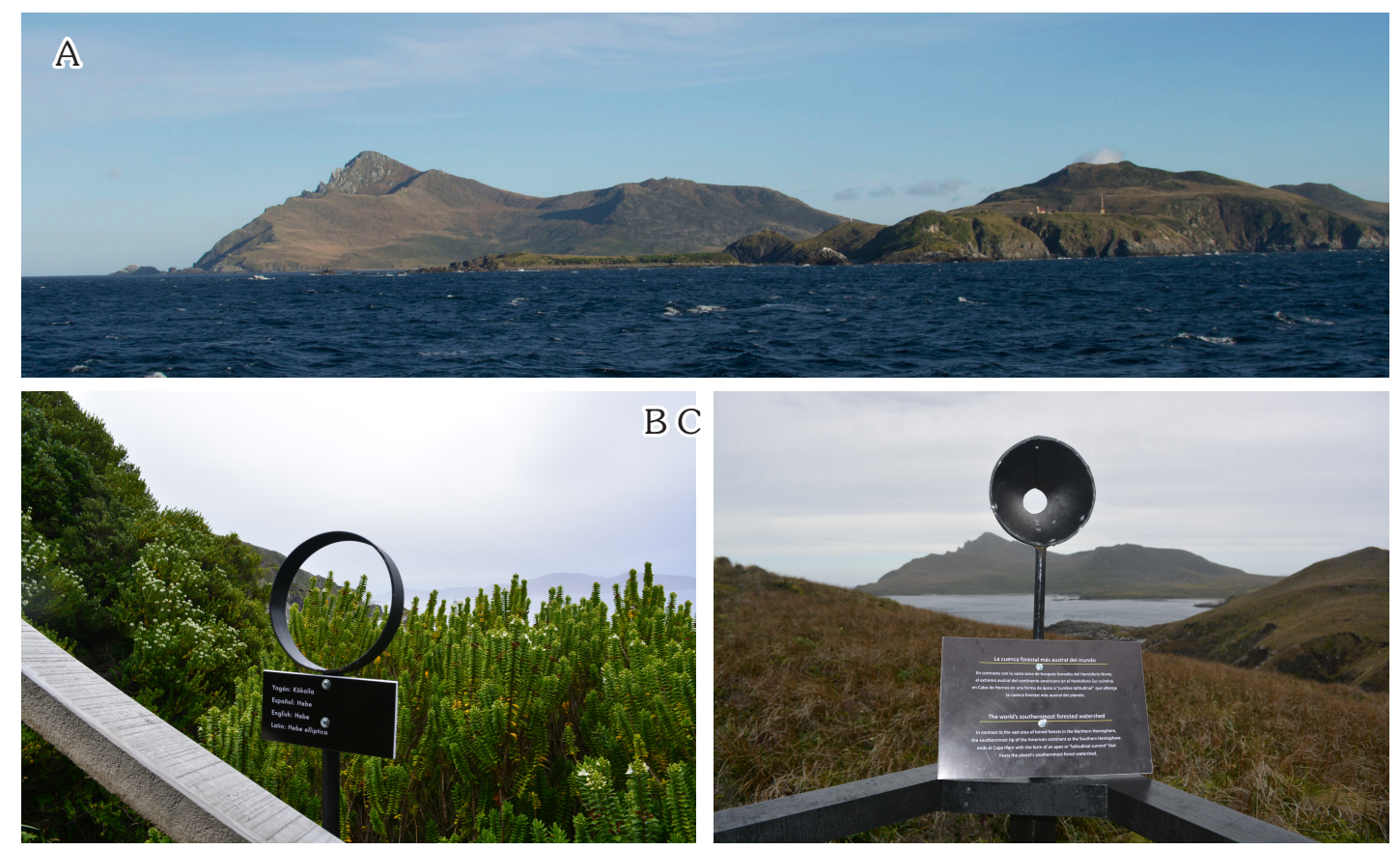

Fig. 7. Sitio Isla Hornos, archipiélago Cabo de Hornos, establecido en las cercanías de la Alcaldía de Mar de la Armada de Chile en el sector sudeste de la isla. A. Vista de las instalaciones de la Alcaldía de Mar y la cuenca forestada más austral del planeta sobre la ladera de exposición este del cerro Pirámide. Entre la Alcaldía de Mar y la cuenca del cerro Pirámide se implementaron puntos de muestreo permanente en ecosistemas terrestres, dulceacuícolas y costero-marinos. En la isla Hornos se ha establecido también un programa de transferencia de la ciencia al turismo de intereses especiales. B. Estructura con forma de lupa para centrar la observación de los turistas en plantas representativas de la vegetación subantártica, como el arbusto Hebe elliptica. Con un enfoque biocultural, las señaléticas indican los nombres de las plantas en lenguas yagán, español, inglés y latín científico. C. Estructura en forma de telescopio para centrar la mirada de los visitantes sobre hitos del paisaje, tales como la cuenca forestada más austral del mundo. Fotografías de Ricardo Rozzi.

velocidad y dirección del viento, temperatura del aire, incluyendo sistema de termómetros seco y húmedo, humedad relativa, presión atmosférica y pluviometría (con totalizador graduado).

Desde la década de 1980, la Armada posee

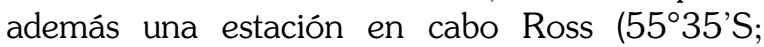
$\left.67^{\circ} 22^{\prime} \mathrm{O}\right)$, isla Wollaston, en el borde noreste del PN Cabo de Hornos. Esta estación ha registrado la velocidad y dirección del viento y presión atmosférica. Los registros de las islas Hornos $y$ Wollaston han sido digitalizados a mano $y$ posteriormente enviados a las oficinas centrales de la Armada de Chile en Valparaíso.

Con la ampliación de la Red LTER-Cabo de Hornos, el año 2021 se complementarán las estaciones de la Armada, tanto en la isla Hornos como en la isla Wollaston, con la instalación de una estación meteorológica automática con registro continuo de las siguientes variables: radiación solar, velocidad y dirección del viento, temperatura del aire, temperatura del suelo, humedad relativa del aire, humedad del suelo y pluviometría. De esta manera, junto al sitio LTER-Isla Hornos en el extremo sur del PN Cabo de Hornos, hemos establecido un punto complementario para el monitoreo climático en el extremo norte de esta área protegida.

c) Ecosistemas terrestres. Edmundo Pisano (1980a) distinguió tres tipos principales de vegetación en el archipiélago Cabo de Hornos: bosques siempreverdes dominados por coigüe de Magallanes, comunidades de turberas heterogéneas pertenecientes al complejo de tundra de Magallanes, y comunidades del "desierto Andino híper-húmedo" o formaciones altoandinas subantárticas. La isla Hornos posee un área de 25,4 $\mathrm{km}^{2}$, donde el complejo de tundra de Magallanes ocupa un $72 \%$, los bosques siempreverdes un $22 \%$ y las formaciones altoandinas restringidas a altitudes por encima de los 300 m ocupan un 
5,8\% del área insular (Rozzi et al. 2006b). En el PN Cabo de Hornos la flora vascular nativa incluye 149 especies y se han registrado sólo seis especies exóticas con una distribución limitada a sitios que han estado sujetos a uso antrópico actual o histórico (Moore \& Goodall, 1977; Dollenz, 1980; Pisano, 1980a, b, 1981, 1982, 1984; Rozzi et al. 2004).

Para la flora no-vascular aún no se habían publicado inventarios. Por lo tanto, uno de los primeros trabajos desarrollados a partir del año 2003 en el Sitio Isla Hornos fue iniciar un inventario de briófitas. Los muestreos realizados hasta noviembre de 2016 han mostrado que la brioflora de la isla Hornos es notablemente diversa y abundante (Goffinet et al. en preparación). Es probable que cumpla también un papel ecológico importante, contribuyendo a la regulación de flujos hidrológicos y de nutrientes en las cuencas de la isla. Por ejemplo, en la ladera de exposición este del cerro Pirámide, habitada por una gran colonia de pingüino de Magallanes Spheniscus magellanicus (Forster, 1781), crecen grandes poblaciones de dos especies de musgo de la familia Splachnaceae: Tayloria dubyi y T. magellanica. Estos musgos podrían estar asociados con los aportes de nutrientes por los pingüinos. En la isla Hornos proyectamos investigar los aportes que los pingüinos de Magallanes y otras aves marinas que nidifican en esta isla hacen a los flujos de nutrientes del suelo (e.g., N, P, K) mediante análisis biogeoquímicos y de isótopos.

En el cerro Pirámide de la isla Hornos, sobre el suelo de las quebradas húmedas que están dominadas por bosques siempreverdes, se extiende una exuberante cubierta de talos del antocerote Nothoceros endiivifolius (Fig. 8A, B). A mayores altitudes, las pequeñas lagunas de agua dulce albergan especies de diversas hepáticas (por ejemplo, del género Jenssenia), y varias lagunas están casi enteramente colonizadas por el musgo Sphagnum falcatulum, que puede crecer hasta unos $50 \mathrm{~cm}$ de longitud. Estas briófitas acuáticas pueden proporcionar hábitats críticos para pequeños invertebrados. En el complejo de tundra de Magallanes se encuentran coloridos mosaicos de hepáticas como Gackstroemia y de elegantes cojines de musgo tales como Dicranoloma robustum. En la zona altoandina, por encima del límite arbóreo, Racomitrium lanuginosum forma cojines conspicuos, constituyendo parches densos y dispersos que pueden alcanzar casi $20 \mathrm{~cm}$ de altura, y podrían aportar a la fijación de nitrógeno (Goffinet et al. en preparación).

Para investigar el potencial impacto del cambio global sobre la flora vascular y novascular, se ha establecido un conjunto de parcelas permanentes con cuadrantes de $1 \times 1 \mathrm{~m}$, equivalentes al instalado en el Sitio Isla Gonzalo, para monitorear los cambios en cobertura $y$ composición de la flora a nivel del suelo (Fig. 8C). Además, en febrero de 2019 se implementaron parcelas permanentes de $10 \times 10 \mathrm{~m}$ en el interior de bosque y de $5 \times 5 \mathrm{~m}$ en los márgenes de bosques en la ladera de exposición este del cerro Pirámide (Fig. 8D) (Buma et al. 2020).

Para los estudios de fauna de vertebrados e invertebrados también se ha adoptado un diseño similar al descrito previamente para el Sitio Isla Gonzalo. Los estudios de aves y mamíferos se iniciaron el año 2002, y una primera síntesis para las comunidades de aves fue descrita por Rozzi y Jiménez (2014) y para los mamíferos por Rozzi et al. (2006a).

En el PN Cabo de Hornos se ha detectado la presencia de 81 especies de aves pertenecientes a 30 familias. La familia más diversa es Anatidae (patos y gansos, 8 especies), seguida por Procellariidae (petreles, 7 especies) (Rozzi et al. 2006a). Entre las especies de anátidos destaca la abundancia de caranca, Chloephaga hybrida (Molina, 1782) y quetru no-volador, Tachyeres pteneres (Forster, 1844), que podría estar asociada a la ausencia del visón norteamericano (Neovison vison (Schreber, 1777). Al carecer de mamíferos depredadores exóticos, la isla Hornos representa un refugio para estas aves y la avifauna de bosque. El límite sur de distribución de varias especies de aves endémicas del bioma de los bosques templados de Sudamérica incluye el comesebo grande (Pygarrhychas albogularis King) y el churrín del sur (Scytalopus magellanicus Gmelin, 1789), que presentan en esta isla mayores abundancias que en otros sectores de la RBCH (Rozzi \& Jiménez, 2014; Crego et al. 2015, Sandvig et al. 2020).

Respecto a los mamíferos, desde el año 2003 se han capturado con trampas Sherman Abrothrix xanthorhinus (Waterhouse, 1837) y no se han detectado roedores exóticos (Rozzi et al. 2006a). La ausencia de roedores exóticos ha 

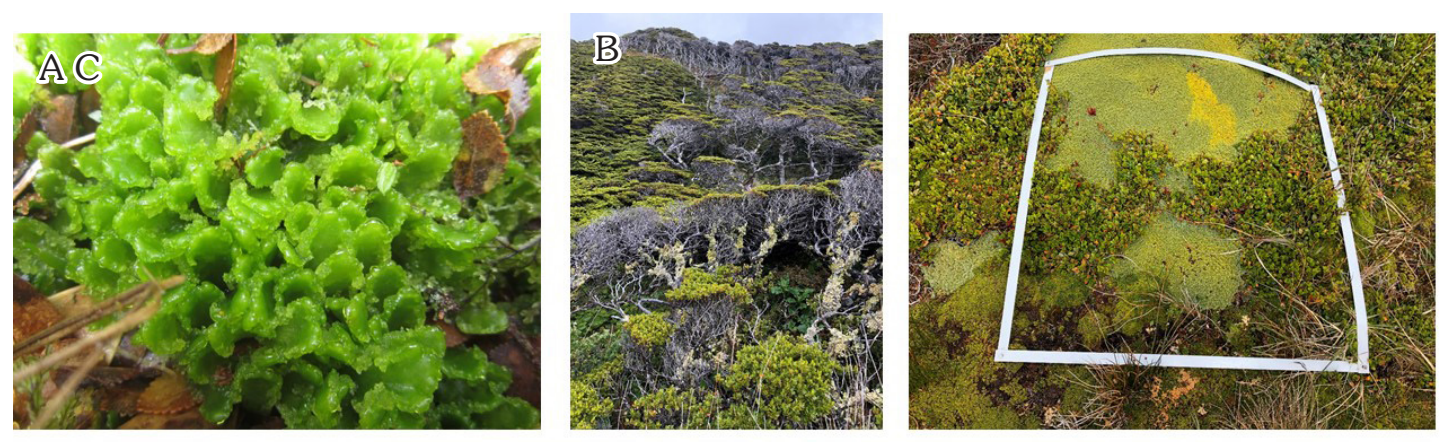

D

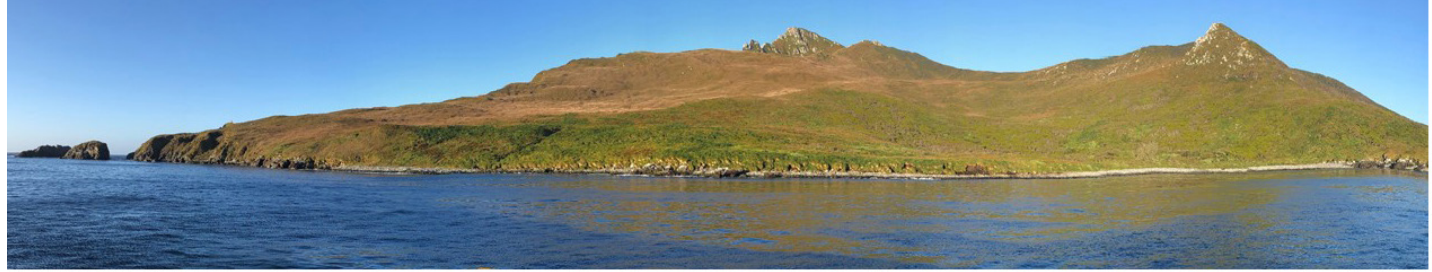

Fig. 8. Estudios ecológicos a largo plazo en la cuenca forestal más austral del planeta en el Sitio LTER-Isla Hornos.

(A) Talos del antocerote Nothoceros endiivifolius. (B) Bosques siempreverdes dominados por coigüe de Magallanes

(Nothofagus betuloides), donde el musgo N. endiivifolius prevalece en la cobertura vegetal del suelo en las quebradas

húmedas. (C) Parcela de 1x1m en los márgenes del bosque, en bahía Espolón, en un punto donde los coigües de

Magallanes crecen en forma rastrera o krumholz, en medio de una tundra dominada por plantas en cojín.

(D) Cuenca forestada en la ladera de exposición este del cerro Pirámide, donde se instalaron las parcelas permanentes de monitoreo del bosque siempreverde. Fotografías de Bernard Goffinet (A) y Ricardo Rozzi (B, C, D).

sido corroborada con el uso de cámaras-trampa instaladas en la vecindad de la Alcaldía de Mar en isla Hornos (Schüttler et al. 2019). En las costas, destaca la presencia de dos especies de nutria con problemas de conservación: el chungungo (Lontra felina Molina, 1782) y el huillín (Lontra provocax Thomas, 1908) (Sepúlveda et al. 2015; Valqui \& Rheingantz, 2015).

d) Ecosistemas dulceacuícolas. Uno de los primeros trabajos fue un mapeo y digitalización de los ecosistemas de agua dulce presentes en la isla Hornos. Para ello se utilizaron los softwares Google Earth Pro y QGIS. Se identificaron 516 lagunas permanentes y 104 esteros (Contador et al., en preparación). Para monitorear variables climáticas y fisicoquímicas del agua (oxígeno disuelto, sólidos disueltos, temperatura, conductividad) se seleccionaron un cuerpo y un curso de agua cercanos a las instalaciones de la Armada. El primero corresponde a una pequeña laguna a $110 \mathrm{msnm}$ (cercano a la línea del límite arbóreo) en la cumbre más cercana al faro de la Armada. El segundo corresponde a un riachuelo en la cuenca del cerro Pirámide (10 msnm). Al igual que en el sitio LTER-Isla Gonzalo, en cada punto de muestreo se instaló un data logger dentro del agua y en el suelo a aproximadamente $5 \mathrm{~m}$ del cuerpo o curso de agua. Con estos dos registros se analizarán las diferencias térmicas y de luminosidad entre el agua y el suelo aledaño.

Las lagunas altoandinas muestreadas son poco profundas $(<2 \mathrm{~m})$ y tienen un sustrato dominado por hepáticas y vegetación vascular (ej. juncos), y en algunos casos por detritus orgánico (hojarasca) de coigüe ( $N$. betuloides). Entre los insectos dulceacuícolas colectados en estos cuerpos de agua, destaca la presencia de al menos cuatro morfotipos de tricópteros limnefilidos (Insecta: Trichoptera: Limnephilidae), coleópteros buceadores (Insecta: Coleoptera: Dytiscidae: Lancetes sp.), mosquitos de las lagunas (Insecta: Diptera: Chironomidae: Tanypodinae), anfípodos (Crustacea: Amphipoda: Hyallelidae: Hyallela sp.), copépodos (Maxillopoda: Calanoida: Centropagidae: Boeckella sp.) y sanguijuelas (Hirudinae), entre otros (Contador et al. en 
preparación). En la zona intermareal superior y medio, se destacó la presencia del mosquito sin alas Halyritus magellanicum (Diptera: Chironomidae). Finalmente, se está trabajando también en la determinación de especies de invertebrados terrestres para elaborar un catastro que servirá de línea de base para monitoreos futuros.

e) Ecosistemas costero-marinos. El mar que rodea a la isla Hornos se caracteriza por una temperatura y salinidad homogéneas en los metros más superficiales, debido principalmente al efecto de la mezcla producido por los fuertes vientos y mareas típicos de la zona (Valdenegro \& Silva, 2003). En las costas de la isla Hornos predominan los sustratos rocosos que proveen hábitats estables para organismos bentónicos como moluscos y macroalgas. En efecto, se han registrado extensas praderas de grandes algas pardas: L. flavicans en la zona intermareal inferior y L. searlesiana entre los 5 y 15 metros, $M$. pyrifera en la zona submareal y D. antarctica en las zonas más expuestas del intermareal (Rozzi et al. 2007). En la isla Hornos se encuentran algunas playas de grandes bolones que también proveen hábitat estable para organismos. Es posible encontrar además ambientes inestables en playas de bolones más pequeños y guijarros que hacen muy difícil para los organismos bentónicos fijarse en su superficie. Hasta la fecha, en las costas de la isla Hornos no se conocen playas de fondos blandos (Rosenfeld \& Ojeda, 2015). Para el monitoreo de biodiversidad costero-marina se ha diseñado un sistema de 10 transectos similar al establecido en el Sitio Isla Gonzalo (Fig. 9). En los primeros resultados de cobertura intermareal
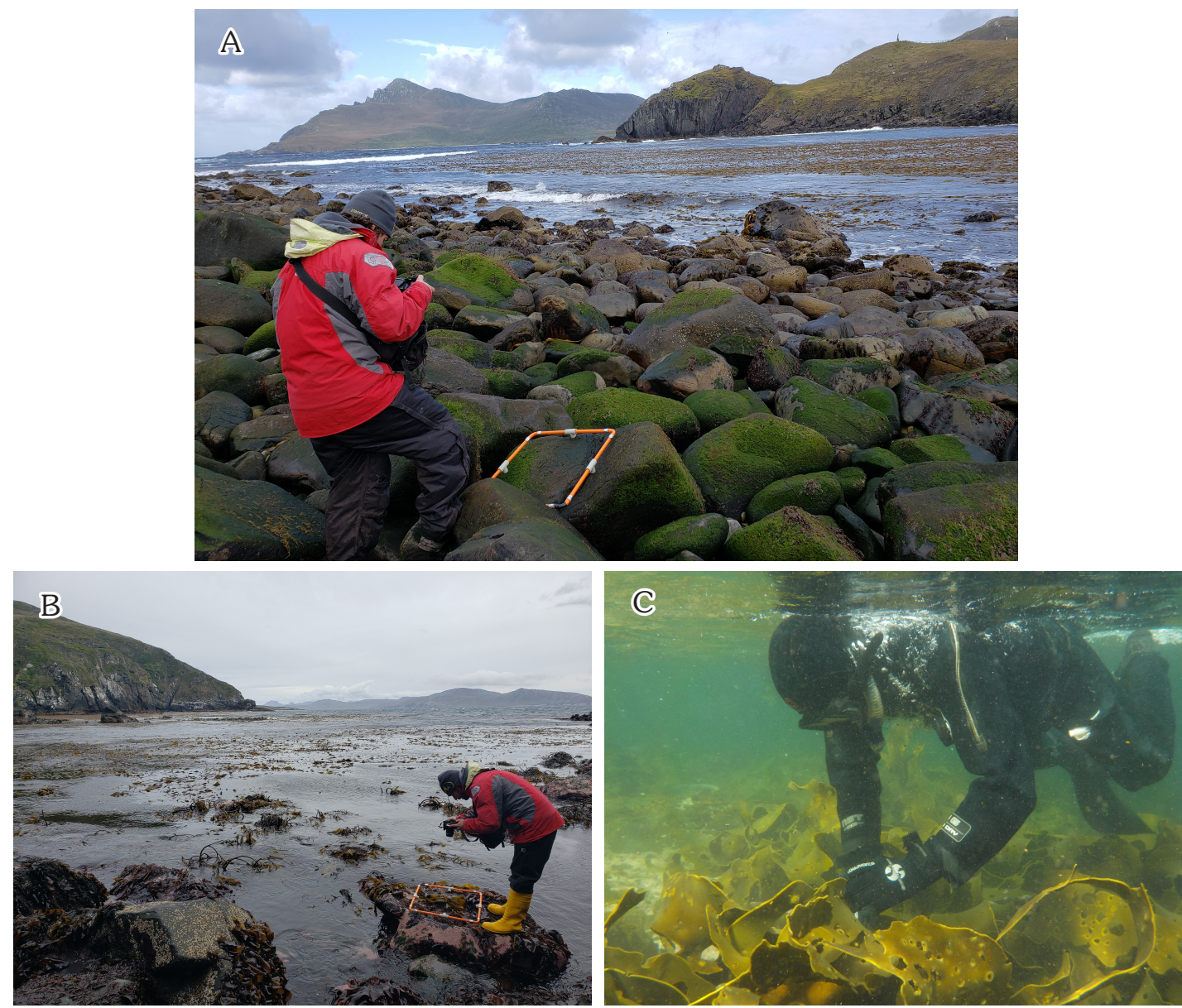

Fig. 9. Sebastián Rosenfeld durante un muestreo en uno de los transectos permanentes inter- y sub-mareales en el Sitio Isla Hornos. Los muestreos se realizan con cuadrantes de $50 \times 50 \mathrm{~cm}$ en los niveles intermareales (A) alto, (B) medio y (C) bajo o submareal. Fotografías de Roy Mackenzie (A, B) y Juan Pablo Rodríguez (C). 
en la isla Hornos se identificaron 27 taxa entre invertebrados sésiles, móviles y macroalgas (Rosenfeld et al. en preparación). Estas cifras difieren de lo registrado previamente por Guzmán y Ríos (1981) para el archipiélago Cabo de Hornos, principalmente porque estos autores evaluaron playas intermareales de bloques y cantos con gran exposición al oleaje. Los primeros inventarios históricos realizados en los primeros 50 metros de profundidad de la isla Hornos han registrado 118 taxa, incluyendo macroalgas, anémonas, esponjas, poliquetos, moluscos, crustáceos, equinodermos y peces. El grupo más diverso es el de macroalgas con 49 especies, seguido por los moluscos con 41 y los crustáceos con 11 (Rosenfeld et al. en preparación).

\section{Sitio Caleta 2 de Mayo}

a) Caracterización administrativa. El Sitio Caleta 2 de Mayo se ubica en la bahía Yendegaia, en las cercanías de la Tenencia Yendegaia de Carabineros de Chile, inaugurada en 1962. Aledaña a esta edificación, la Dirección General de Aguas (DGA) instaló una estación meteorológica el año 2009. Caleta 2 de Mayo se encuentra adyacente al límite sudeste del PN Yendegaia que cubre un área de $150.587,3$ ha y es administrado por CONAF. En este contexto, para la implementación de este sitio suscribimos convenios de colaboración con Carabineros de Chile, la DGA y CONAF.

En colaboración con CONAF, el 2014 iniciamos exploraciones y pilotos de monitoreo en lugares complementarios de la bahía Yendegaia, en sectores del valle del río Yendegaia y caleta Ferrari. El 2017 se adicionó el punto de monitoreo en caleta Contreras (Fig. 2). La información técnica del sitio LTER-Bahía Yendegaia estará disponible a partir del 2021 en el repositorio de la Red ILTER en el sitio web DEIMS-SDR. Este sitio se encuentra en una zona con distintos grados de impacto antrópico, donde la actividad humana ha aumentado rápidamente debido a la construcción de la Ruta Vicuña-Yendegaia, que culminará en caleta 2 de Mayo dentro de la próxima década. La mayor conectividad conllevará un aumento del flujo turístico y actividades productivas (Rozzi et al. 2006b), aumentando riesgos de potenciales arribos de especies domésticas e invasoras (Schüttler et al. 2019). Por lo tanto, para este sitio cobra alta relevancia el monitoreo de especies exóticas y más ampliamente la evaluación del cambio socioecológico (Fig. 10).

b) Caracterización biofísica y climática. El área de la bahía Yendegaia se ubica en una zona ecotonal, definida por un pronunciado gradiente de humedad desde el extremo oeste de Tierra del Fuego (donde los ecosistemas dominados por bosques siempreverdes reciben precipitaciones anuales de $5.000 \mathrm{~mm}$ ) hasta el sector este de Yendegaia, donde los ecosistemas dominados por bosques deciduos reciben una precipitación anual en un orden de magnitud menor (Rozzi et al. 2007). En la ciudad vecina de Ushuaia, Argentina, ubicada $20 \mathrm{~km}$ hacia el este, la temperatura anual media es $5,8^{\circ} \mathrm{C}$ y la precipitación anual media es 529 mm (Universidad Nacional de La Plata, 2017).

Respecto al equipamiento meteorológico, desde el año 2016 la DGA ha registrado (i) temperatura del aire, (ii) humedad relativa del aire, presión atmosférica y (iii) pluviometría, con una estación meteorológica automática que realiza registro continuo de estas variables. Los datos están disponibles en internet (http://dgasatel.mop. $\mathrm{cl} /$ ). Dado el interés científico y en el monitoreo ambiental en Yendegaia, con la ampliación de la Red LTER-Cabo de Hornos se suscribió un convenio de colaboración entre la DGA y el Programa CBS (coordinado por UMAG, IEB y Fundación Omora) el año 2020. En base a este convenio, el Programa CBS complementó la estación meteorológica DGAYendegaia con nuevos sensores de temperatura del aire, humedad relativa del aire, radiación solar, pluviómetro (con calentador para condiciones de precipitación sólida), altura de nieve, temperatura y humedad del suelo. Además, se recomendó relocalizar la estación automática de la DGA puesto que estaba ubicada a menos de 10 metros de la Tenencia Yendegaia. El año 2020 se trasladó a un sitio aledaño ubicado a $200 \mathrm{~m}$ del edificio (5452'4”S; 6841'17”O).

En el Sitio LTER-Caleta 2 de Mayo se implementaron varios puntos complementarios de monitoreo. Primeramente, aledaño al glaciar Fouque (55²'10”S; 69³2'20”O) se instaló una estación de registros climáticos automáticos que mide temperatura y humedad atmosférica, radiación solar, precipitación y velocidad/ 

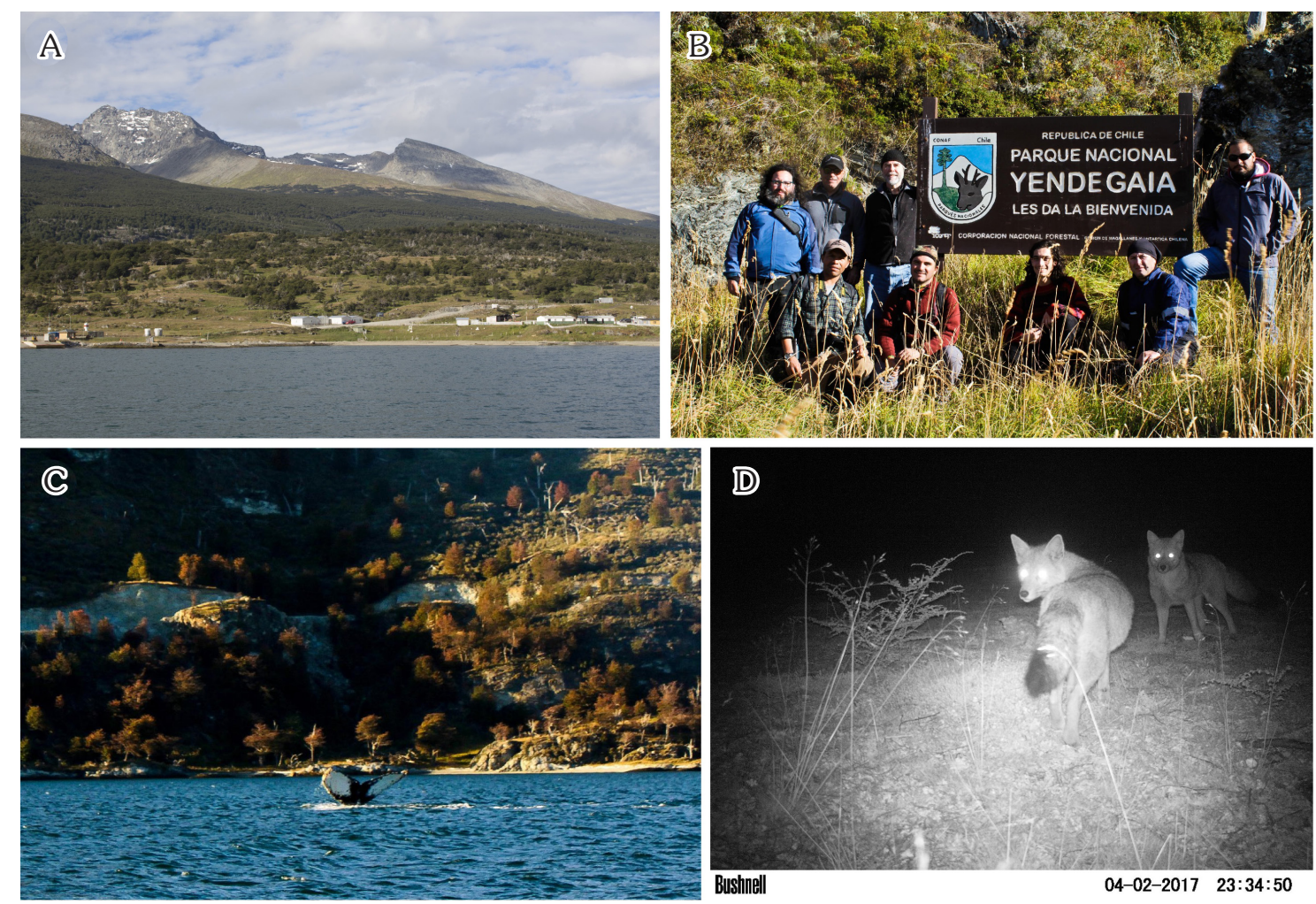

Fig. 10. Sitio LTER-Caleta 2 de Mayo adyacente al límite sudeste del PN Yendegaia, incluyendo también sitios de monitoreo dentro del parque nacional. (A) Vista de caleta 2 de Mayo tomada en diciembre de 2016 desde bahía Yendegaia, mostrando la rampa del puerto y la Tenencia de Carabineros que provee colaboración al sitio LTER. (B) Punto de estudios complementarios en la entrada al PN Yendegaia en caleta Ferrari, con un grupo de profesionales de CONAF y del Programa de Conservación Biocultural Subantártica en la expedición de abril de 2017. (C) Aleta caudal (o cola) de ballena jorobada (Megaptera novaeangliae Borowski, 1781) cercana a la costa oriental de la bahía Yendegaia, donde se construye el camino Vicuña-Yendegaia, para el cual se propone un diseño como ruta escénica. (D) Zorro culpeo fueguino registrado con cámaras-trampa durante el primer monitoreo en el lugar de estudios complementarios de caleta Ferrari, diciembre de 2014. Fotografías de Ricardo Rozzi (A), Cristián Valle (B y C) y Eduardo Silva-Rodríguez (D).

dirección del viento, en febrero de 2019. Este es el glaciar más austral del continente americano que desciende hasta el mar (Fig. 11). Se encuentra en la isla Hoste, en la costa oeste del canal Fouque que se extiende hacia el sur desde el Brazo Suroeste del Canal Beagle, en el PN Alberto de Agostini.

En segundo lugar, otros puntos complementarios de monitoreo están ubicados dentro del PN Alberto de Agostini, incluyen el fiordo Pía $\left(54^{\circ} 47^{\prime} \mathrm{S}\right.$; $\left.69^{\circ} 35^{\prime} \mathrm{O}\right)$, el glaciar Alemania (545' S; 69 $\left.24^{\prime} \mathrm{O}\right)$ y la caleta Olla (545'ㅇ; 6909'O) (Fig. 2). En estos puntos se han tomado datos climáticos, muestreos de flora y fauna y estudios ecológicos desde el año 2000 (Rozzi \& Jiménez, 2014; Crego et al. 2015). En el fiordo Pía, brazos oeste y este, especialmente en el frente de los glaciares Sinus y Kalv, se han realizado estudios de sucesión ecológica asociados a la dinámica de retrocesos y avances de glaciares (Arróniz-Crespo et al. 2014; Fernández-Martínez et al. 2017; Green et al. 2017; BenaventGonzález et al. 2019). El fiordo Pía se extiende hacia el norte desde el Brazo Noroeste del Canal Beagle adentrándose a la vertiente sur (exposición polar) de la cordillera Darwin.

En tercer lugar, en febrero de 2019 los puntos complementarios de monitoreo ubicados dentro o en la vecindad del PN Yendegaia incluyen parcelas vegetacionales adyacentes a Hito 26 en la costa norte del canal Beagle, y desde el 2015 se han realizado estudios en puntos ubicados en el valle del río Yendegaia y frente del glaciar Stopani, 

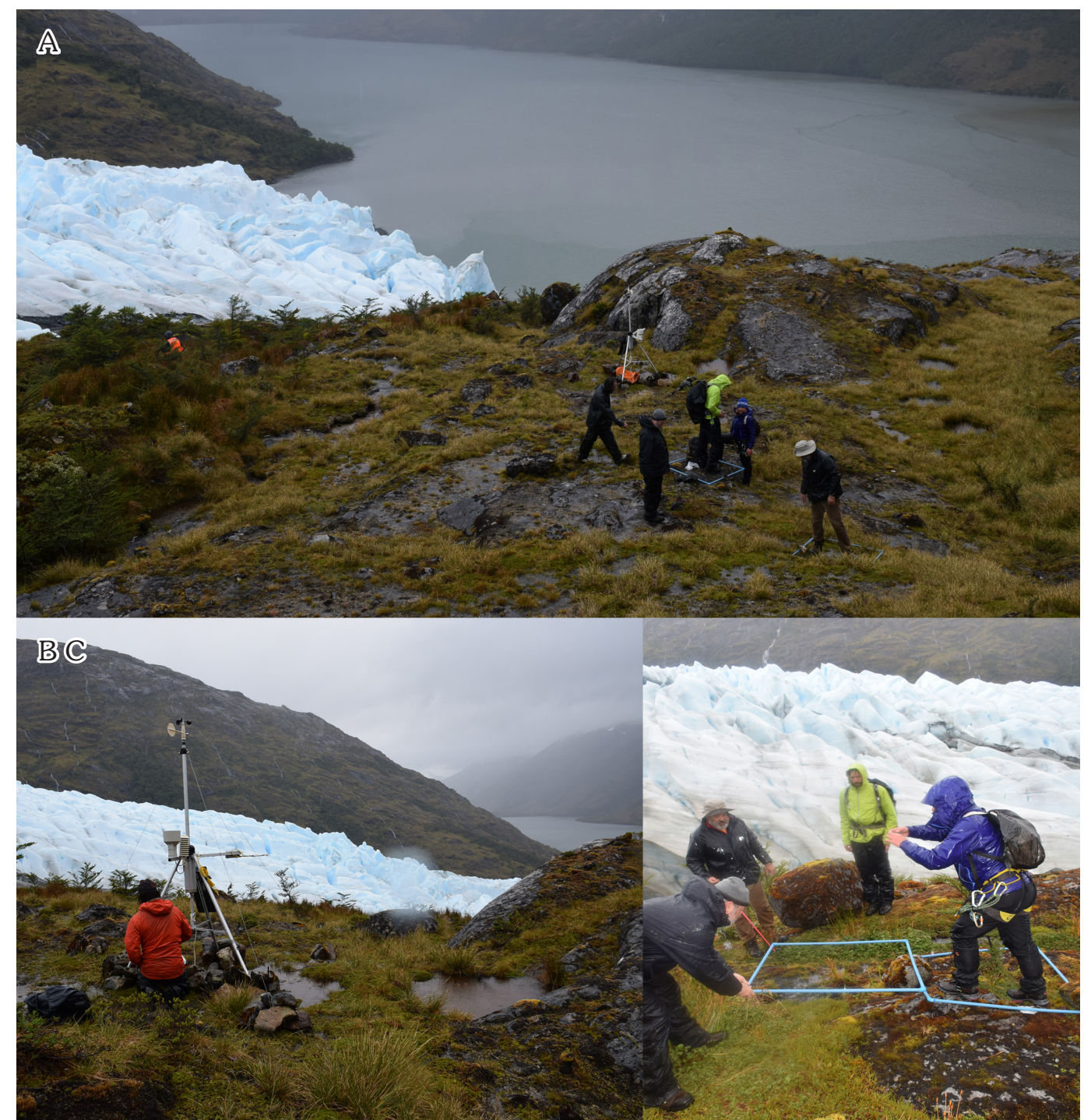

Fig. 11. Glaciar Fouque como punto de monitoreo complementario asociado al Sitio LTER-Caleta 2 de Mayo. A. Vista del fiordo Fouque con el glaciar Fouque y vegetación de tundra y colonización de bosque en el margen sur del glaciar. B. Detalle de la estación meteorológica automática (Vaisala) provista por la DGA durante el proceso de instalación en febrero de 2019. C. Cuadrantes de 1x1m para monitorear la dinámica de vegetación aledaña al glaciar. Fotografías de Ignacio Palma.

sectores costeros y de praderas y formaciones arbustivas antropogénicas en caleta Ferrari $y$ sectores costeros y bosques siempreverdes en caleta Contreras (Fig. 2).

c) Ecosistemas terrestres. Desde el nivel del mar hasta los $550 \mathrm{~m}$ de altitud, las laderas montañosas de la bahía Yendegaia están cubiertas de bosques, que en el sector este de la bahía estuvieron sujetos a extensas talas y quemas durante el siglo XX (Rozzi et al. 2006a). Tal como en otros sectores de la $\mathrm{RBCH}$, por sobre el limite arbóreo prevalecen comunidades de estepas altoandinas de plantas en cojín, entre 550 y 800 msnm (Rozzi et al. 2006b; Molina et al. 2016). Por sobre los $1.000 \mathrm{~m}$, las cumbres del sector oeste del PN Yendegaia están cubiertas por glaciares que descienden hacia los valles, generando numerosos cursos de aguas y quebradas. En las zonas bajas de la bahía Yendegaia prevalecen turberas y otras formaciones del complejo de tundra de Magallanes 
(sensu Pisano, 1977), junto a lagunas, bosques ribereños, vegas y otras formaciones de humedales costeros (Rozzi et al. 2006b).

Para investigar el potencial impacto del cambio global sobre la flora vascular y no-vascular, se ha establecido un conjunto de parcelas permanentes con cuadrantes de $1 \times 1 \mathrm{~m}$ para monitorear los cambios en composición y cobertura, equivalente al instalado en el Sitio Isla Gonzalo. En febrero de 2019, para monitorear cambios en diversidad y cobertura de la vegetación baja, tres cuadrantes de $1 \times 1 \mathrm{~m}$ se ubicaron en un sitio de interior bosque mixto ( $N$. betuloides y $N$. pumilio) y en margen de bosque con formaciones de matorral dominado por Chiliotrichum diffusum (G. Forst.) Kuntze aledaño al Hito 26 (5453'36”'S; 68³6'25”O, cuadrantes de margen de bosque), en la frontera entre Chile y Argentina por la costa norte del canal Beagle. Además, en caleta 2 de Mayo, en las proximidades de la Tenencia de Carabineros, se inició un catastro de plantas vasculares exóticas asociadas al uso antrópico de la costa y laderas orientales de la bahía Yendegaia. Se registraron 16 especies herbáceas propias de praderas naturalizadas, entre las cuales Dactylis glomerata L., Trifolium repens L. y Taraxacum officinale (L.) Weber ex F. H. Wigg. fueron especialmente abundantes. Además, se colectó Stellaria media (L.) Vill. registrada previamente por Pisano (1980a). En el interior de bosque, la ocurrencia de plantas exóticas fue muy escasa (Sánchez-Jardón et al. en preparación).

Nuestro monitoreo de vertebrados en los puntos de estudio asociados al Sitio Caleta 2 de Mayo ha registrado una rica avifauna, con al menos 62 especies de aves terrestres y costero-marinas (Sandvig et al. 2020). Destaca la abundancia de rapaces diurnas y nocturnas que incluyen águila mora (Geranoaetus melanoleucus Vieillot, 1819), cernícalo (Falco sparverius Linnaeus, 1758), concón (Strix rufipes King, 1828), tucúquere (Bubo magellanicus Gmelin, 1788) y chuncho (Glaucidium nanum King, 1828). La abundancia de rapaces podría estar asociada a la disponibilidad de roedores nativos (Oligoryzomys longicaudatus, Abrothrix xanthorhinus y A. longipilis) y exóticos (rata almizclera (Ondatra zibethicus Linnaeus, 1766 y castor (Castor canadensis Kuhl, 1820), como también conejo (Oryctolagus cuniculus Linnaeus, 1758) (Castillo et al. 2017). En los bosques siempreverdes de los puntos glaciar Alemania y caleta Olla destaca la abundancia de paseriformes, del psitácido cachaña (Enicognathus ferrugineus Müller, 1776) y picaflor chico (Sephanoides sephaniodes (Lesson, 1827)). El gorrión (Passer domesticus Linnaeus, 1758) es la única especie de ave exótica, presente solamente en caleta 2 de Mayo en sectores cercanos a las construcciones humanas.

Entre los mamíferos resalta el zorro culpeo fueguino (Lycalopex culpaeus lycoides Philippi, 1896) (Castillo et al. 2017). Muestreos preliminares (2017) sugieren alta frecuencia de esta especie (Silva-Rodríguez et al. en preparación). Otros mamíferos con presencia confirmada en los parques nacionales Yendegaia y de Agostini incluyen al guanaco (Lama guanicoe P. L. S. Müller, 1776), huillin y roedores de los géneros Abrothrix xanthorhinus xanthorhinus (Waterhouse, 1837) y Oligoryzomys longicaudatus magellanicus (Bennett, 1832). Es notoria aquí la abundancia y diversidad de mamíferos exóticos invasores, donde destaca la presencia del castor (Castor canadensis) que ocupa casi la totalidad de las cuencas en el sector de la bahía Yendegaia, produciendo una drástica modificación del paisaje (Baldini et al. 2008; Schüttler et al. 2019).

Los caballos asilvestrados (Equus caballus Linnaeus, 1758) son comunes en una extensa zona del PN Yendegaia (Silva-Rodríguez et al. en preparación). Un intento de extraer los caballos durante el proceso de donación de la Estancia Yendegaia al Ministerio de Bienes Nacionales generó una seria controversia que finalmente se resolvió cesando el manejo de los animales (SilvaRodríguez et al. en preparación). Otras especies exóticas invasoras detectadas incluyen conejo (Oryctolagus cuniculus Linnaeus, 1758), visón norteamericano (Neovison vison Schreber, 1777) y perros (Canis familiaris Linnaeus, 1758), algunos de estos últimos con propietarios locales (Silva-Rodríguez et al. en preparación). En la actualidad, y asociado al proceso de elaboración e implementación del Plan de Manejo del PN Yendegaia, CONAF ha propuesto un plan de monitoreo con cámaras-trampa que considera el seguimiento de indicadores vinculados tanto a objetos de conservación (e.g., zorro culpeo fueguino) como a amenazas (e.g., ganado bagual). 
La fauna de invertebrados también incluye registros de insectos exóticos invasores. En marzo de 2017, la avispa chaqueta amarilla (Vespula vulgaris Linnaeus, 1758) y el abejorro europeo (Bombus terrestris Linnaeus, 1758) se detectaron en los puntos de monitoreo de caleta 2 de Mayo, caleta Ferrari y caleta Contreras en la bahía Yendegaia (Fig. 2). Para controlar y monitorear el avance de la invasión de chaqueta amarilla en la zona se propone instalar trampas de cebo (Rendoll-Cárcamo et al. 2016). Respecto a los invertebrados terrestres nativos, en marzo-abril de 2017 se identificaron mediante el uso de trampas Malaise y trampas pitfall, 54 taxa de 13 órdenes (Rendoll-Cárcamo et al. en preparación). Es necesario complementar estos muestreos iniciales con censos en primavera y verano para construir una línea de base representativa.

d) Ecosistemas dulceacuícolas. Las laderas de los cordones montañosos que rodean la bahía Yendegaia están surcadas por numerosos cursos de agua de distintos tamaños. En el trabajo de campo (marzo de 2017) se muestrearon dos riachuelos vecinos a la caleta 2 de Mayo, uno en caleta Ferrari $y$ uno en caleta Contreras. Se ha implementado el registro de variables fisicoquímicas del agua y de invertebrados dulceacuícolas con redes surber y trampas Malaise para imagos emergentes, con la misma metodología utilizada en la isla Hornos. Hasta el momento se han colectado más de 3000 individuos pertenecientes a seis clases y 10 órdenes (Rendoll-Cárcamo et al. en preparación). Estos registros han servido como línea de base para la elaboración del Plan de Manejo del PN Yendegaia. Hemos advertido también respecto al peligro de invasión por didymo (Didymosphenia geminata (Lyngbye) M. Schmidt, 1899), alga exótica invasora presente al norte de Tierra del Fuego (CONAF, en preparación). Finalmente, en puntos de monitoreo ubicados en el PN Alberto de Agostini hemos detectado con redes de pesca la presencia de salmonideos, principalmente de salmón coho (Oncorhynchus kisutch (Walbaum, 1792)) (Rozzi, datos sin publicar).

e) Ecosistemas costero-marinos. Bahía Yendegaia recibe descargas de agua del deshielo de los glaciares que influyen sobre sus características térmicas, salinas y nutritivas (Valdenegro \& Silva, 2003). Los tipos de playa incluyen sustratos de terrazas rocosas, guijarros y bolones pequeños, y fondos blandos en los sectores aledaños a la desembocadura del río Yendegaia, que provee una zona de alimentación para numerosas especies de aves y un hábitat para invertebrados marinos como almejas y poliquetos (Rosenfeld et al. 2015). Se ha iniciado un catastro de macroalgas, esponjas, moluscos, cirripedios, crustáceos, equinodermos y peces (Rodríguez et al. en preparación).

El estudio costero-marino permitirá monitorear el estado de conservación de este hábitat clave para el huillín y las aves costeras, y detectar tempranamente el arribo de especies de algas exóticas. En sectores costeros aledaños a la caleta 2 de Mayo, se realizaron en marzo de 2017 muestreos en distintos niveles del intermareal con formaciones de terrazas rocosas, que procurarán establecer cuadrantes permanentes para censos de primavera $y$ otoño, con foto-registro $e$ interpretación. La diversidad de especies está siendo analizada en el Laboratorio de Macroalgas de la UMAG (Rodríguez et al. en preparación).

\section{COMENTARIOS FINALES Y VISIÓN DESDE LA RBCH}

El cumplimiento de la función de apoyo logístico a la $\mathrm{RBCH}$ se consolidará con la inauguración del Centro Subantártico Cabo de Hornos (CESACH) en Puerto Williams el año 2021. Este centro coordinará la red de sitios LTERCabo de Hornos en estrecha colaboración con la Red LTSER-Chile, y proveerá un sitio habilitado para consultar la información pública. Además, ofrecerá cursos que transferirán a la ciudadanía conocimientos de biodiversidad generados en la Red LTER-Cabo de Hornos y aportarán antecedentes para un modelo de desarrollo sustentable. Para contribuir a la integración del bienestar social, económico y ambiental, consistente con el Programa MaB de UNESCO y el Parque Marino Islas Diego Ramírez-Paso Drake, el futuro Centro Subantártico Cabo de Hornos estará organizado arquitectónicamente en tres módulos.

A escala local, surgen nuevos desafíos. El CESACH y la Red LTER-Cabo de Hornos están llamados a informar la toma de decisiones, tanto en la $\mathrm{RBCH}$ como en las Áreas Silvestres Protegidas que la integran. Importantes inversiones que el 
Estado realiza a través del financiamiento de la actividad científica (e.g., proyectos FONDECYT, becas de postgrado, PIA-CONICYT, entre otros), adquieren mayor relevancia para la sociedad cuando la información que producen permite reducir la incertidumbre inherente a procesos de toma de decisiones. Existen importantes diferencias en objetivos, lenguajes y plazos entre el trabajo de los científicos y el de los tomadores de decisiones (véase Sarewitz, 2004; Bainbridge, 2014; Silva-Rodríguez et al. 2018). Para superar estas diferencias, el CESACH fortalecerá el trabajo colaborativo transdisciplinario e inter-institucional, apoyando procesos de planificación en la $\mathrm{RBCH}$. De hecho, este tipo de colaboraciones ayudará a elaborar los planes de manejo de los tres parques nacionales de la $\mathrm{RBCH}$ : Yendegaia, Alberto de Agostini y Cabo de Hornos. Adicionalmente, se requiere una mirada de futuro, donde el $\mathrm{CESACH}$ apoye su información en la revisión, medición y análisis de indicadores identificados como parte de dichos procesos, poniendo sus capacidades científicas al servicio de la sociedad; así no será sólo una fuente de información para entender los procesos de cambio global, sino que contribuirá a la gestión y evaluación de la efectividad de las acciones que, a escala local, se toman para prevenir, mitigar o revertir dichos procesos. Esto es parte esencial de la responsabilidad social y ambiental de un centro de investigación de carácter público como el CESACH. El nuevo Parque Marino Islas Diego RamírezPaso Drake y la $\mathrm{RBCH}$ protegen ecosistemas marinos, dulceacuícolas y terrestres únicos en el mundo, donde todavía se puede asumir una aproximación proactiva en favor de la conservación biocultural. Esta oportunidad es más recomendable que una aproximación reactiva centrada en restaurar ecosistemas o mitigar impactos negativos, como ya ha ocurrido en otras reservas de la biosfera de Chile (Moreira \& Borsdorf, 2014; Rozzi \& Schüttler, 2015; Moreira et al. 2019). Para ello, por un lado, el CESACH y la Red LTER-Cabo de Hornos monitorearán el cambio socio-ambiental global y su impacto sobre la biodiversidad de la $\mathrm{RBCH}$. Con el fin de ampliar la cobertura, en el próximo quinquenio se incorporará un mayor número de puntos de monitoreo complementarios a cada uno de los sitios LTER-Cabo de Hornos. Por otro lado, los programas de investigación, educación y transferencia del
CESACH procurarán orientar un modelo de desarrollo sustentable a escala local, fortaleciendo los programas de capacitación en Puerto Williams y sitios de la Red LTER-Cabo de Hornos.

A escala global, pondremos en marcha una combinación innovadora de programas de colaboración con dos redes internacionales: $\mathrm{MaB}$ UNESCO e ILTER. Esta combinación de modelos de la red de monitoreo ecológico a largo plazo integrados con la red mundial de reservas de la biosfera como plataforma de apoyo logístico a la investigación y educación en la $\mathrm{RBCH}$, contribuirá a observar, valorar y proteger la biodiversidad del extremo austral de Sudamérica. En este sentido, desde el 2021 el Parque Omora medirá flujos de gases de efecto invernadero en ecosistemas forestales y turberas, y podrá incorporarse a FLUXNET y AMERIFLUX como el sitio de monitoreo más austral del continente americano.

El CESACH concibe la integración de escalas biofísicas y socio-culturales a través de la incorporación complementaria de disciplinas científicas y humanistas. Es fundamental fortalecer la participación de miembros de la comunidad yagán, quienes poseen distintos oficios y formas de saber ancestral; de la comunidad huillichemapuche de isla Navarino, quienes también aportan conocimientos ecológicos tradicionales de su pueblo originario; y de miembros de las organizaciones de pescadores, operadores turísticos y otros oficios, quienes aportan saberes prácticos esenciales. El CESACH y la Red LTER-Cabo de Hornos aspiran a incrementar la representación de ecosistemas en los estudios ecológicos a largo plazo y las formas de saberes provenientes del sur del mundo.

Para el monitoreo del cambio global, el CESACH asumirá el papel de un centro de pensamiento (think tank), como institución académica centrada en la investigación subantártica con una perspectiva comparativa en ecosistemas dentro del hemisferio sur y con experiencias subpolares del hemisferio norte. El CESACH ofrecerá modelos de investigación, educación y conservación para los ecosistemas subantárticos, de manera análoga a aquella de la Organización de Estudios Tropicales (OET, fundada en los 1960s y coordinada por la Universidad de Costa Rica y la Universidad de Duke en EE.UU.; http://www. ots.duke.edu) para los ecosistemas tropicales. 
El CESACH robustecerá el descubrimiento de la singular biodiversidad subantártica terrestre, dulceacuícola y marina, y la comunicación de su importancia planetaria. Los equipos de la OET y CESACH han colaborado, y este último fortalecerá la complementación entre estos dos programas en tres aspectos fundamentales: i) respecto al área geográfica, su foco se centra en ecosistemas subantárticos que han recibido menor atención para la conservación que los ecosistemas tropicales; (ii) respecto a la metodología de sus cursos, CESACH continuará fomentando la participación conjunta de investigadores y estudiantes chilenos, latinoamericanos y de otras regiones del mundo, metodología que contrasta con la de OET que ofrece cursos separados para estadounidenses y latinoamericanos; (iii) respecto al foco temático, la OET ha enfatizado la investigación ecológica $y$ ha incorporado recientemente variables socio-ecológicas (principalmente socioeconómicas), complementariamente en la próxima década, CESACH procurará consolidar en la teoría y práctica de la investigación, la educación y la conservación biocultural, incluyendo el turismo de intereses especiales, la integración entre las ciencias ecológicas, las artes y las humanidades, principalmente la ética ambiental (Rozzi et al. 2010).

Ubicada en la "cumbre austral" de América, Puerto Williams, la capital de la Provincia Antártica Chilena, podrá emerger como un polo mundial de investigación científica transdisciplinaria subantártica, equipado con un nuevo polo mundial de investigación y red de estudios socio-ecológicos a largo plazo. La colaboración con actores regionales, nacionales $e$ internacionales permitirá que la Red LTER-Cabo de Hornos y el CESACH, junto a la red LTSER-Chile, aporten datos críticos que abrirán nuevas oportunidades para el monitoreo del cambio climático y su impacto sobre la biodiversidad y ecosistemas en latitudes subantárticas. El monitoreo constituye también un componente esencial para aumentar efectivamente las acciones de mitigación y adaptación. Además, desde el sur del mundo permitirá fortalecer un modelo de desarrollo local sustentable que, asociado a la $\mathrm{RBCH}$, aporte a la conservación biocultural y a satisfacer las necesidades de bienestar socioeconómico y sustentabilidad ambiental a múltiples escalas regionales y planetarias.

\section{AGRADECIMIENTOS}

Agradecemos a la Armada de Chile, Carabineros de Chile, Corporación Nacional Forestal, Dirección General de Aguas del Ministerio de Obras Públicas, Ministerio del Medio Ambiente, Ministerio de Bienes Nacionales, Subsecretaría de Pesca y Subsecretaría de Turismo del Ministerio de Economía, Fomento y Turismo por el apoyo logístico y de capacidades humanas en las expediciones, diseño y desarrollo de los estudios ecológicos a largo plazo en la Reserva de la Biosfera Cabo de Hornos y Parque Marino Islas Diego Ramírez - Paso Drake. A John Engel y Matt von Konrat por la identificación de las hepáticas provenientes de la isla Hornos y Diego Ramírez, y a Cristian Frene y un revisor anónimo por sus valiosos comentarios. Este trabajo ha contado con el apoyo de los proyectos Instituto de Ecología y Biodiversidad (IEB) de Chile a través del proyecto Centros Tecnológicos de Excelencia con Financiamiento Basal ANID AFB170008; FONDEQUIP-CONICYT y Bienes Públicos-CORFO a la Universidad de Magallanes (UMAG); Grupo de Trabajo Mar y Tierra (The Pew Charitable Trust-Chile) a la Fundación Omora; Núcleo INVASAL al Laboratorio Wankara-UMAG, y The National Geographic Society (NGS 147S18) que cofinanció una expedición e investigación en el sitio de estudios en isla Hornos. Esta es una contribución del Programa CBS, conjuntamente coordinado por IEB, UMAG y University of North Texas (UNT).

\section{LITERATURA CITADA}

Aguirre, J. (2015). Hermeneutics and field environmental philosophy: integrating ecological sciences and ethics into Earth stewardship. In R. Rozzi, F. S. Chapin, J. B. Callicott, S. T. A. Pickett, M. Power, J. J. Armesto, \& R. H. May Jr. (Eds.), Earth stewardship: linking ecology and ethics in theory and practice (pp. 235-247). Dordrecht: Springer.

Anderson, C. B., Rozzi, R., Armesto, J. J., \& Gutiérrez, J. R. (2010). Construyendo una red chilena para estudios socioecológicos a largo plazo: avances, enfoques y relevancia. Revista chilena de historia natural, 83(1), 


\section{$1-11$.}

Antonelli, A., Zizka, A., Carvalho, F. A., Scharn, R., Bacon, C. D., Silvestro, D., \& Condamine, F.L. (2018). Amazonia is the primary source of Neotropical biodiversity. Proceedings of the National Academy of Sciences, 115, 6034-6039.

Aravena, J. C., Lara, A., Wolodarky-Franke, A., Villalba, R., \& Cuq, E. (2002). Treering growth patterns and temperature reconstruction from Nothofagus pumilio (Fagaceae) forest at the upper tree line of southern Chilean Patagonia. Revista Chilena de Historia Natural, 75, 361-376.

Armesto, J. J., Rozzi, R., Smith-Ramírez, C., \& Arroyo, M. T. K. (1998). Conservation targets in South American temperate forests. Science, 282, 1271-1272.

Arróniz-Crespo, M., Pérez-Ortega, S., de los Ríos, A., Green, T. G. A., Ochoa-Hueso, R., Casermeiro, M. A., de la Cruz, M. T., A. Pintado, D. Palacios, R. Rozzi, N. Tysklind, \& Sancho, L. G. (2014). Bryophytecyanobacteria associations during primary succession in recently deglaciated areas of Tierra del Fuego (Chile). PLoS ONE, 9(5), e96081.

Bainbridge, I. (2014). How can ecologists make conservation policy more evidence based? Ideas and examples from a devolved perspective. Journal of Applied Ecology, $51,1153-1158$.

Baldini, A., Oltremari, J., \& Ramírez, M. (2008). Impacto del castor (Castor canadensis, Rodentia) en bosques de lenga (Nothofagus pumilio) de Tierra del Fuego, Chile. Bosque, 29(2), 162-169.

Barroso, O., Crego, R. D., Mella, J., Rosenfeld, S., Contador, T., Mackenzie, R., Vásquez, R., \& Rozzi, R. (2020). Colaboración científica con la Armada de Chile en estudios ornitológicos a largo plazo en el archipiélago Diego Ramírez: primer monitoreo del ciclo anual del ensamble de aves en isla Gonzalo. Anales del Instituto de la Patagonia, 48(3), 149-168.

Benavent-González, A., Raggio, J., Villagra, J., Blanquer, J. M., Pintado, A., Rozzi, R., Green, T. G. A., \& Sancho, L. (2019).
High nitrogen contribution by Gunnera magellanica and nitrogen transfer by mycorrhizae drive an extraordinarily fast primary succession in Sub-Antarctic Chile. New Phytologist, 223(2), 661-674.

Benedetti-Cecchi, L., \& Cinelli, F. (1997). Spatial distribution of algae and invertebrates in the rocky intertidal zone of the Strait of Magellan, are patterns general? Polar Biology, 18, 337-343.

Buma, B., Holz, A., Díaz, I., \& Rozzi, R. (2020). The world's southernmost tree and global southern treeline. Ecography, 43, 1-11.

Carmona, M. R., Aravena, J. C., BustamanteSánchez, M. A., Celis-Diez, J. L., Charrier, A., Díaz, I. A., \& Armesto, J. J. (2010). Estación Biológica Senda Darwin: Investigación Ecológica De Largo plazo en la interfase ciencia-sociedad. Revista Chilena de Historia Natural, 83, 113-142.

Castillo, S., Crego, R. D., Jiménez, J. E., \& Rozzi, R. (2017). Native-predator-invasive-prey trophic interactions in Tierra del Fuego: the beginning of biological resistance? Ecology, 98(9), 2485-2487.

Chapin III, F. S., Jefferies, R. L., Reynolds, J. F., Shaver, G. R., Svoboda, J., \& Chu, E. W. (Eds.) (1991). Arctic ecosystems in a changing climate: an ecophysiological perspective. Academic Press: San Diego.

Contador, T. A., Kennedy, J. H., \& Rozzi, R. (2012). The conservation status of southern South American aquatic insects in the literature. Biodiversity and Conservation, 21, 2095-2107.

Contador, T. A., Kennedy, J. H., Ojeda, J., Feinsinger, P., \& Rozzi, R. (2014). Ciclos de vida de insectos dulceacuícolas y cambio climático global en la ecorregión subantártica de Magallanes: investigaciones ecológicas a largo plazo en el Parque Etnobotánico Omora, Reserva de Biosfera Cabo de Hornos (55 S). Bosque, 35, 429-437.

Contador, T. A., Kennedy, J. H., Rozzi, R., \& Ojeda, J. (2015). Sharp altitudinal gradients in Magellanic sub-Antarctic streams: thermal patterns and benthic macroinvertebrate communities along a fluvial system in the Cape Horn Biosphere Reserve $\left(55^{\circ} \mathrm{S}\right)$. Polar 
Biology, 38, 1853-1866.

Contador, T., R. Rozzi, J. Kennedy, F. Massardo, J. Ojeda, P. Caballero, Y. Medina, R. Molina, F. Saldivia, F. Berchez, A. Stambuk, V. Morales, K. Moses, M. Gañan, G. Arriagada, J. Rendoll, F. Olivares, S. Lazzarino. (2018). Sumergidos con lupa en los ríos del Cabo de Hornos: Valoración ética de los ecosistemas dulceacuícolas y sus co-habitantes. Magallania, 46(1), 183-206.

Contador, T., Rendoll, J., Mackenzie, R., Rosenfeld, S., Barroso, O., Rozzi, R., Goffinet, B., Kennedy, J., \& Convey, P. (2020). Comunidades de invertebrados terrestres del archipiélago Diego Ramírez (56³1’S), el sitio de estudios socio-ecológicos a largo plazo más austral de América: diversidad y afinidades con las islas sub-antárticas del Océano Austral. Anales del Instituto de la Patagonia, 48(3), 83-98.

Contreras, D., Schlatter, D. R., \& Ramírez, C. (1983). Flora ficológica de las Islas Diego Ramírez (Chile). Serie Científica Instituto Antártico Chileno, 30, 13-26.

Crego, R. D., Jiménez, J. E., \& Rozzi, R. (2015). Expansión de la invasión del visón norteamericano (Neovison vison) en la Reserva de la Biosfera Cabo de Hornos, Chile. Anales del Instituto de la Patagonia, 43(1), 157-162.

Crego, R. D., Ward, N., Jiménez, J. E., Massardo, F., \& Rozzi, R. (2018a). Los ojos del árbol: percibiendo, registrando, comprendiendo y contrarrestando las invasiones biológicas en tiempos de rápida homogeneización biocultural. Magallania, 46(1), 137-153.

Crego, R. D., Jiménez, J. E., \& Rozzi, R. (2018b). Potential niche expansion of the American mink invading a remote island free of nativepredatory mammals. PLoS ONE, 13, p.e0194745.

Crego, R. D., Jiménez, J. E., \& Rozzi, R. (2018c). Macro-and micro-habitat selection of small rodents and their predation risk perception under a novel invasive predator at the southern end of the Americas. Mammal Research 63, 267-275. https://doi. org/10.1007/s13364-018-0361-5

Diario Oficial (25 de julio, 1945). Decreto
995/1945 del Ministerio de Tierras y Colonización que crea el Parque Nacional Cabo de Hornos. https://www.leychile.cl/ Navegar?idNorma $=269839$ [Consultado Julio 25, 2019]

Diario Oficial (21 de enero, 2019). Decreto 9/2019 del Ministerio del Medio Ambiente que crea el Parque Marino Islas Diego Ramírez y Paso Drake https://www.leychile.cl/ Navegar?idNorma $=1128077$ [Consultado Julio 25, 2019]

Djukic, I., Kepfer-Rojas, S., Kappel-Schmidt, I., Steenberg-Larsen, K. C. Beierb, B. Bergcd, K. Verheyene. (2018). Early stage litter decomposition across biomes. Science of the Total Environment, 628-629, 13691394.

Dollenz, O. (1980). Estudios fitosociológicos en archipiélago Cabo de Hornos. I. Relevamientos en Caleta Lientur, Isla Wollaston y Surgidero Romanche, Isla Bayly. Anales Instituto Patagonia, 11, 225-238.

Dornelas, M., Antao, L. H., Moyes, F., Bates, A. E., Magurran, A. E., Adam, D., Akhmetzhanova, A., Appeltans, W, Arcos, J. M., Arnold, H., Ayyappan, N., Badihi, G., Baird, A. H., Barbosa, M., Barreto, T. E., Bässler, C., Bellgrove, A., Belmaker, J., Benedetti-Cecchi, L., Bett, B. J., Bjorkman, A. D., et al. (2018). BioTIME: A database of biodiversity time series for the Anthropocene. Global Ecology and Biogeography, 27(7), 760-786.

Fernández-Martínez, M. A., Pointing, S. B., Pérez-Ortega, S., Arróniz-Crespo, M., Green, T.G.A., Rozzi, R., Sancho, L. G., \& de los Ríos, A. (2017). Microbial succession dynamics along glacier forefield chronosequences in Tierra del Fuego (Chile). Polar Biology, 40, 1-19.

Goffinet, B., Rozzi, R., Lewis, L., Buck, W., \& Massardo, F. (2012). The miniature forests of Cape Horn: eco-tourism with a handlens ("Los bosques en miniatura del Cabo de Hornos: ecoturismo con lupa"). Bilingual English-Spanish edition. Denton, TX and Punta Arenas, Chile: UNT Press-Ediciones Universidad de Magallanes.

Goffinet, B., Engel, J. J., von Konrat, M., Mackenzie, 
R., Contador, T., Rosenfeld, S., Barroso, O., \& Rozzi, R. (2020). First bryophyte records from Diego Ramírez archipelago: changing lenses in long-term socio-ecological research at the southernmost island of the Americas. Anales del Instituto de la Patagonia, 48(3), 127-138.

Green, T. G. A., Sancho, L.G., Pintado, A., Saco, D., Martín-Gómez, M. S., Arróniz-Crespo, M., Casermeiro, M. A., de la Cruz Caravaca, M. T., Cameron, S., \& Rozzi, R. (2017). Obligate sodium chloride accumulation in plants with cyanobacterial symbionts. $A o B$ Plants, 9(6), p.plx053.

Greenslade, P., \& Convey, P. (2012). Exotic Collembola on subantarctic islands: pathways, origins and biology. Biological Invasions, 14(2), 405-417.

Guevara, S., \& Laborde, J. (2008). The Landscape Approach: Designing new reserves for protection of biological and cultural diversity in Latin America. Environmental Ethics, 30, 251-262.

Gutiérrez, J. R., Meserve, P. L., Kelt, D. A., Engilis Jr., A., \& Andrea, M. (2010). Long-term research in Bosque Fray Jorge National Park: Twenty years studying the role of biotic and abiotic factors in a Chilean semiarid scrubland. Revista Chilena de Historia Natural, 83, 69-98.

Guzmán, L., \& Ríos, C. (1981). Estructura del conjunto de macroorganismos de una playa de bloques y cantos rodados de Isla Wollaston, Archipiélago del Cabo de Hornos. Anales del Instituto de la Patagonia, 12, 258-270.

Hänel, C., Chown, S. L., \& Davies, L. (1998). Records of alien insect species from subAntarctic Marion and South Georgia Islands. African Entomology, 6(2), 366-369.

Hassan, R., Scholes, R., \& Ash, N. (2005). Millenium Ecosystem Assessment. Ecosystems and human well-being: current state and trends. Vol. 1. Island Press: Washington, DC.

Hedin, L. O., Armesto, J. J., \& Johnson, A. H. (1995). Patterns of nutrient from unpolluted, old-growth temperate forest: Evaluation of biogeochemical theory. Ecology, 76, 493-
509.

Holzer, J. M., Adamescu, M. C., Bonet-García, F. J., Díaz-Delgado, R., Dick, J., Grove, J. M.,Rozzi, R., \& Orenstein, D. E. (2018). Negotiating local versus global needs in the International Long Term Ecological Research Network's socio-ecological research agenda. Environmental Research Letters, 13(10), 105003.

ILTER (2006). International Long-Term Ecological Research (ILTER) Network Strategic Plan. Retrieved from https://www.ilter.network/ sites/default/files/ILTER\%20Strategic\%20 Plan.pdf. Accessed February 17, 2018.

Jägerbrand, A. K., Alatalo, J. M., Chrimes, D., \& Molau, U. (2009). Plant community responses to 5 years of simulated climate change in meadow and heath ecosystems at a subarctic-alpine site. Oecologia, 161(3), 601-610.

Jones, H. P., Tershy, B. R., Zavaleta, E. S., Croll, D. A., Keitt, B. S., Finkelstein, M. E., \& Howald, G. R. (2008). Severity of the effects of invasive rats on seabirds: A global review. Conservation Biology, 22, 16-26.

Karez, C. S., Hernández-Faccio, J. M., Schüttler, E., Rozzi, R., García, M., Meza, A. Y., \& Clüsener-Godt, M. (2016). Learning experiences about intangible heritage conservation for sustainability in biosphere reserves. Special Issue on "Intangible Cultural Heritage". Material Culture Review, 82-83, 84-96.

Koch, G. W., Vitousek, P. M., Steffen, W. L., \& Walker, B. H. (1995). Terrestrial transects for global change research. Vegetatio, 121, 53-65.

Körner, C. (2003). Alpine plant life: functional plant ecology of high mountain ecosystems. Springer: Berlin.

Lawford, R. G., Alaback, P. B., \& Fuentes, E. (Eds.) (1996). High-Latitude Rainforests and Associated Ecosystems of the West Coast of the Americas: Climate, Hydrology, Ecology, and Conservation. Springer: New York.

Lawler, J. J., Aukema, J. E., Grant, J. B., Halpern, B. S., Kareiva, P., Nelson, C. R., Ohleth, K., Olden, J. D., Schlaepfer, M. A., Silliman, 
B. R., \& Zaradic, P. (2006). Conservation science: a 20-year report card. Frontiers in Ecology and the Environment, 4, 473480.

Lebouvier, M., Laparie, M., Hulle, M., Marais, A., Cozic, Y., Lalouette, L., Vernon P., Candresse T., Frenot Y., \& Renault, D. (2011). The significance of the sub-Antarctic Kerguelen Islands for the assessment of the vulnerability of native communities to climate change, alien insect invasions and plant viruses. Biological Invasions, 13(5), 1195-1208.

Lewis, P. N., Riddle, M. J., \& Smith, S. D. (2005). Assisted passage or passive drift: a comparison of alternative transport mechanisms for non-indigenous coastal species into the Southern Ocean. Antarctic Science, 17(2), 183-191.

Lewis, L., Gottschalk-Druschke, C., Saldías, C., Mackenzie, R., Malebrán, J., Goffinet, B., \& Rozzi, R. (2018). Cultivando un jardín de nombres en los bosques en miniatura del Cabo de Hornos: extensión de la conservación biocultural y la ética a seres vivos poco percibidos. Magallania, 46(1), 103-123.

Li, B., Parr, T., \& Rozzi, R. (2015). Geographical and thematic distribution of publications generated at the International Long-Term Ecological Research Network (ILTER) Sites. In R. Rozzi, F. S. Chapin, J. B. Callicott, S. T. A. Pickett, M. E. Power, J. J. Armesto \& R.H. May Jr. (Eds.), Earth stewardship: Linking ecology and ethics in theory and practice (pp. 195-216). Dordrecht, Netherlands: Springer.

Maass, M., Balvanera, P., Bourgeron, P., Equihua, M., Baudry, J., Dick, J., Forsius, M., Halada, L., Krauze, K., Nakaoka, M., Orenstein, D. E., Parr, T. W., Redman, C. L., Rozzi, R., Santos-Reis, M., Swemmer, A. M., \& Vadineanu, A. (2016). Changes in biodiversity and trade-offs among ecosystem services, stakeholders, and components of well-being: the contribution of the International Long-Term Ecological Research network (ILTER) to Programme on Ecosystem Change and Society (PECS).
Ecology and Society, 21(31), http://dx.doi. org/10.5751/ES-08587-210331

Mach, P. M., Winfield, J. L., Aguilera, R. A., Wright, K. C., \& Verbeck, G. F. (2017). A portable mass spectrometer study targeting anthropogenic contaminantsinSub-Antarctic Puerto Williams, Chile. International Journal of Mass Spectrometry, 422, 148153.

Mackenzie, R., Vidal, O., Rosenfeld, S., Contador, T., Barroso, O., Goffinet, B., Massardo, F., Arce-Johnson, P., \& Rozzi, R. (2020). Flora vascular y formaciones vegetacionales en el sitio de estudios socio-ecológicos a largo plazo, isla Gonzalo, archipiélago Diego Ramírez (563'ㄴ), Chile. Anales del Instituto de la Patagonia, 48(3), 139-148.

Malebrán, J., \& Rozzi, R. (2018). Análisis de los cursos de filosofía ambiental de campo en el Parque Etnobotánico Omora, Reserva de la Biosfera Cabo de Hornos, Chile. Magallania, 46(1), 207-225.

Mansilla, A., \& Navarro, N. (2003). Contribución al estudio de la flora ficológica de las islas Diego Ramírez (Chile). En A. Mansilla, C. Werlinger \& N. Navarro (Eds.), Memorias curso internacional de postgrado y especialización de macroalgas en ambientes subantárticos (pp. 85-89). Punta Arenas: Ediciones Universidad de Magallanes.

Mansilla, A., Ávila, M., Cáceres, J., Palacios, M., Navarro, N., Cañete, I., \& Oyarzún, S. (2009). Diagnóstico bases biológicas explotación sustentable Macrocystis pyrifera, (Huiro), XII Región. Código BIP N³0060262-0. Gobierno Regional de Magallanes y Antártica Chilena. Punta Arenas: Universidad de Magallanes.

Marambio, J., Rosenfeld, S., Rodríguez, J. P., Méndez, F., Contador, T., Mackenzie, R., Goffinet, B., Rozzi, R., \& Mansilla, A. (2020). Siete nuevos registros de macroalgas para el archipiélago Diego Ramírez (56 $31^{\circ}$ 'S): el valor del nuevo parque marino como sumidero de carbono y conservación de la biodiversidad subantártica. Anales del Instituto de la Patagonia, 48(3), 99-1118. Méndez, M., Rozzi, R., \& Cavieres, L. (2013). Flora 
vascular y no-vascular en la zona altoandina de la isla Navarino $\left(55^{\circ} \mathrm{S}\right)$, Reserva de Biosfera Cabo de Hornos, Chile. Gayana Botanica, 70, 337-343.

Méndez, M. O., Cavieres, L., \& Rozzi, R. (2018). Jardineras subantárticas: conocimiento y valoración de la flora altoandina. Magallania, 46(1), 125-135.

Molina, A. J., Lumbreras, A., Benavent-González, A., Rozzi, R., \& Sancho, L. G. (2016). Plant communities as bioclimate indicators on Isla Navarino, one of the southernmost forested areas of the world. Gayana Botanica, 73, 391-401.

Moore, D. M. (1983). The flora of the FuegoPatagonian Cordilleras: its origins and affinities. Revista Chilena de Historia Natural, 56, 123-136.

Moore, D. M., \& Goodall, R. N. (1977). La flora adventicia de Tierra del Fuego. Anales del Instituto de la Patagonia, 8, 263-274.

Moreira Muñoz, A., \& Borsdorf, A. (2014). Reservas de la Biosfera de Chile: Laboratorios para la Sustentabilidad. Chile: Instituto de Geografía.

Moreira-Muñoz, A., Carvajal, F., Elórtegui, S., \& Rozzi, R. (2019). The Chilean biosphere reserves network as a model for sustainability? In M. G. Reed \& M. F. Price, eds., UNESCO Biosphere Reserves: Supporting Biocultural Diversity, Sustainability and Society. Abingdon, UK: Routledge.

Murray, S. N., Ambrose, R. F., \& Dethier, M. N. (2002). Methods for performing monitoring, impact, and ecological studies on rocky shores. MMS OCS Study 2001070.

Myers, N., Mittermeier, R. A., Mittermeier, C. G., da Fonseca, G. A. B., \& Kent, J. (2000). Biodiversity hotspots for conservation priorities. Nature, 403, 853-858.

Ojeda, J., Marambio, J., Rosenfeld, S., Rozzi, R., \& Mansilla, A. (2014). Patrones estacionales y espaciales de la diversidad de moluscos intermareales de bahía Róbalo, canal Beagle, Reserva de la Biosfera Cabo de Hornos, Chile. Revista de Biología Marina y Oceanografía, 49, 493-509.

Ojeda, J., Rozzi, R., Rosenfeld, S., Contador, T.,
Massardo, F., Malebrán, J., ... \& Mansilla, A. (2018). Interacciones bioculturales del pueblo yagán con las macroalgas y moluscos: una aproximación desde la filosofía ambiental de campo. Magallania, 46(1), 155-181.

Ojeda, J., Marambio, J., Rosenfeld, S., Contador, T., Rozzi, R., \& Mansilla, A. (2019). Temporal changes of macroalgae assemblage on rocky shores of the Cape Horn Biosphere Reserve, Sub-Antarctic Channels, Chile. Aquatic Botany, 157, 33-41.

Pisano, E. (1972). Observaciones fito-ecológicas en las islas Diego Ramírez. Anales del Instituto de la Patagonia, 3, 161-169.

Pisano, E. (1977). Fitogeografía de FuegoPatagonia chilena. I. Comunidades vegetales entre las latitudes $52^{\circ}$ y $56^{\circ} \mathrm{S}$. Anales del Instituto de la Patagonia, 8, 121-250.

Pisano, E. (1980a). Catálogo de la flora vascular del archipiélago del Cabo de Hornos. Anales del Instituto de la Patagonia, 11, 151-189.

Pisano, E. (1980b). Distribución y características de la vegetación del archipiélago del Cabo de Hornos. Anales del Instituto de la Patagonia, 11, 191-224.

Pisano, E. (1981). Bosquejo fitogeográfico de Fuego-Patagonia. Anales del Instituto de la Patagonia, 12, 159-171.

Pisano, E. (1982). Adiciones a la flora vascular del archipiélago del Cabo de Hornos. Anales del Instituto de la Patagonia, 13, 153-159.

Pisano, E. (1984). Relaciones circumantárticas de la flora vascular del archipiélago del Cabo de Hornos. Anales del Instituto de la Patagonia, 15, 5-24.

Pisano, E., \& Schlatter, R. P. (1981). Vegetación y flora de las islas Diego Ramírez (Chile).

1. Características y relaciones de la flora vascular. Anales del Instituto de la Patagonia, 12, 183-194.

Rendoll-Cárcamo, J., Contador, T., Crego, R. D., Jordán, N. I., Schüttler, E., Gañán, M., Jiménez, J. E., Rozzi, R., Massardo, F., \& Kennedy, J. H. (2016). Primer registro de Vespula vulgaris (Linnaeus 1758) (Hymenoptera: Vespidae) en la isla Navarino, Chile. Gayana, 80, 133-136. 
Rendoll-Cárcamo, J., Contador, T., \& Zúñiga, L. M. (2017a). Observaciones sobre robo primario de néctar de Vespula vulgaris L., 1758 (Hymenoptera: Vespidae) en flores de Embothrium coccineum (J. R. Forst. \& G. Forst., 1775) (Proteaceae) en el sur de Chile $\left(55^{\circ} \mathrm{S}\right)$. Anales del Instituto de la Patagonia, 45, 65-70.

Rendoll-Cárcamo, J. A., Contador, T. A., Saavedra, L., \& Montalva, J. (2017b). First record of the invasive bumblebee Bombus terrestris (Hymenoptera: Apidae) on Navarino Island, southern Chile $\left(55^{\circ} \mathrm{S}\right)$. Journal of Melittology, 71, 1-5.

Rendoll Cárcamo, J., Contador, T., Gañán, M., Pérez, C., Maldonado, A., Convey, P., Kennedy, J.H., \& Rozzi, R. (2019). Altitudinal gradients in Magellanic subAntarctic lagoons: the effect of elevation on freshwater macroinvertebrate diversity and distribution. PeerJ, 7, e7128 http://doi. org/10.7717/peerj.7128

Robertson, G., Moreno, C. A., Lawton, K., Arata, J., Valencia, J., \& Kirkwood, R. (2007). An estimate of the population sizes of Blackbrowed (Thalassarche melanophris) and Grey-headed ( $T$. chrysostoma) albatrosses breeding in the Diego Ramírez Archipelago, Chile. Emu, 107, 239-244.

Robertson, G., Wienecke, B., Suazo, C. G., Lawton, K., Arata, J., \& Moreno, C. (2017). Continued increase in the number of black-browed albatrosses (Thalassarche melanophris) at Diego Ramírez, Chile. Polar Biology, 40, 1035-1042.

Rosenfeld, S., \& Ojeda, O. (2015). HabitantesHábitats y Hábitos marinos. En T. Contador, S. Rosenfeld, J. Ojeda, \& J. Kennedy (Eds.), Historia natural de los invertebrados del Cabo de Hornos (pp. 40-51). Punta Arenas, Chile: Ediciones Universidad de Magallanes.

Rosenfeld, S., Ojeda, J., Hüne, M., Mansilla, A., \& Contador, T. (2014). Egg masses of the Patagonian squid Doryteuthis (Amerigo) gahi attached to giant kelp (Macrocystis pyrifera) in the sub-Antarctic ecoregion. Polar Research, 33, 21636. https://doi. org/10.3402/polar.v33.21636.

Rosenfeld, S., Aldea, C., Ojeda, J., Hüne, M.,
Marambio, J., \& Mansilla, A. (2015). Habitantes marinos. En T. Contador, S. Rosenfeld, J. Ojeda, \& J. Kennedy (Eds.), Historia natural de los invertebrados del Cabo de Hornos (pp. 105-179). Punta Arenas, Chile: Ediciones Universidad de Magallanes.

Rosenfeld, S., Marambio, J., Aldea, C., Rodríguez, J. P., Méndez, F., González-Wevar, C., Gerard, K., Contador, T., Mackenzie, R., Rozzi, R., \& Mansilla, A. (2020). Actualización del catastro de ensamble de moluscos costero-marinos del archipiélago Diego Ramírez (56 $31^{\circ}$ 'S), Chile: un refugio para la economía sustentable y conservación subantártica. Anales del Instituto de la Patagonia, 48(3), 113-125.

Rozzi, R. (2002). Biological and cultural conservation in the archipelago forest ecosystems of southern Chile. Ph.D. Dissertation. Department of Ecology and Evolutionary Biology, University of Connecticut, USA.

Rozzi, R. (2018). Cabo de Hornos: un crisol biogeográfico en la cumbre austral de América. Magallania, 46(1), 79-101.

Rozzi, R., \& Jiménez, J. E. (Eds.). (2014). Magellanic subantarctic ornithology: First decade of forest bird studies at the Omora Ethnobotanical Park, Cape Horn Biosphere Reserve. Denton TX, USA Punta Arenas, Chile: UNT Press-Ediciones Universidad de Magallanes.

Rozzi, R., \& Schüttler, E. (2015). Primera década de investigación y educación en la Reserva de la Biosfera Cabo de Hornos: el enfoque biocultural del Parque Etnobotánico Omora. Anales del Instituto de la Patagonia, 43, 75-99.

Rozzi, R., Charlin, R., Ippi, S., \& Dollenz, O. (2004). Cabo de Hornos: un parque nacional libre de especies exóticas en el confín de América. Anales del Instituto de la Patagonia, 32, 55-62.

Rozzi, R., Massardo, F., Anderson, C. B., Heidinger, K., \& Silander Jr, J. A. (2006a). Ten principles for biocultural conservation at the southern tip of the Americas: the approach of the Omora Ethnobotanical Park. Ecology 
and Society, 11(1), 43 [online] URL: http:// www.ecologyandsociety.org/vol11/iss1/ art43/

Rozzi, R., Massardo, F., Berghöfer, A., Anderson, C., Mansilla, A., Mansilla, M., Plana, J., Berghöfer, U., Barros, E., \& Araya, P. (2006b). The Cape Horn Biosphere Reserve. Punta Arenas, Chile: Ediciones Universidad de Magallanes.

Rozzi, R., Massardo, F., Mansilla, A., Anderson, C. B., Berghöfer, A., Mansilla, M., Gallardo, M.R.,...\& Barros, E. (2007). La reserva de biosfera Cabo de Hornos: un desafío para la conservación de la biodiversidad e implementación del desarrollo sustentable en el extremo austral de América. Anales del Instituto de la Patagonia, 35, 55-70.

Rozzi, R., Armesto, J., Goffinet, B., Buck, W., Massardo, F., Silander, J., Kalin-Arroyo, M., Russell, S., Anderson, C. B., Cavieres, L., \& Callicott, J. B. (2008a). Changing lenses to assess biodiversity: patterns of species richness in sub-Antarctic plants and implications for global conservation. Frontiers in Ecology and the Environment, 6, 131-137.

Rozzi, R., Armesto, J. J., \& Frodeman, R. (2008b). Integrando las ciencias ecológicas y la ética ambiental en la conservación biocultural de los ecosistemas templados subantárticos de Sudamérica. Environmental Ethics, 30, 9-16.

Rozzi, R., Arango, X., Massardo, F., Anderson, C., Heidinger, K., \& Moses, K. (2008c). Filosofía ambiental de campo y conservación biocultural: el programa educativo del Parque Etnobotánico Omora. Environmental Ethics, 30, 115-128.

Rozzi, R., Anderson, C. B., Pizarro, J. C., Massardo, F., Medina, Y., Mansilla, A., Kennedy, J. H., Ojeda, J., Contador, T., Morales, V., Moses, K., Poole, A., Armesto, J. J., \& Kalin, M. T. (2010). Filosofía ambiental de campo y conservación biocultural en el Parque Etnobotánico Omora: aproximaciones metodológicas para ampliar los modos de integrar el componente social ("S") en Sitios de Estudios Socio-Ecológicos a Largo Plazo (SESELP). Revista Chilena de Historia
Natural, 83, 27-68.

Rozzi, R., Armesto, J. J., Gutiérrez, J., Massardo, F., Likens, G., Anderson, C. B., Poole, A., Moses, K., Hargrove, G., Mansilla, A., Kennedy, J. H., Willson, M., Jax, K., Jones, C., Callicott, J. B., \& Kalin, M. T. (2012). Integrating ecology and environmental ethics: Earth stewardship in the southern end of the Americas. BioScience, 62, 226236.

Rozzi, R., Massardo, F., Contador, T., Crego, R. D., Méndez, M., Rijal, R., Cavieres, L., \& Jiménez, J. E. (2014). Filosofía ambiental de campo: ecología y ética en las redes LTERChile e ILTER. Bosque, 35, 439-447.

Rozzi, R., Chapin III, F. S., Callicott, J. B., Power, M. E., Pickett, S. T. A., Armesto, J. J., \& May Jr., R. H. (2015). Linking ecology and ethics for an interregional and intercultural earth stewardship. In R. Rozzi, F.S. Chapin III, J. B. Callicott, S.T.A. Pickett, M.E. Power, J.J. Armesto, \& R.H. May Jr., (Eds.), Earth stewardship: Linking ecology and ethics in theory and practice, Ecology and Ethics Series (pp. 1-16). Ecology \& Ethics Series, vol 2. Netherlands: Springer, Dordrecht.

Rozzi, R., Massardo, F., Mansilla, A., Squeo, F. A., Barros, E., Contador, T., Frangópulos, M., Poulin, E., Rosenfeld, S., Goffinet, B., González-Wevar, C., Mackenzie, R., Crego, R. D., Viddi, F., Naretto, J., Gallardo, M. R., Jiménez, J. E., Marambio, J., Pérez, C.,... \& Martinic, M. (2017). Parque Marino Cabo de Hornos-Diego Ramírez. Technical report to the proposal for creation of the Cape Horn - Diego Ramírez Marine Park. Punta Arenas, Chile: Ediciones Universidad de Magallanes. https://issuu.com/umag9/ docs/ebook_low_parque_marino_umag_ fin_di

Sandvig, E. M., Quilodrán, C.S., Aguirre, F., Rivero de Aguilar, J., Barroso, O., Vasquéz, R.A., \& Rozzi, R. 2020. Aviturismo y patrones de distribución de la avifauna de los bosques de la Reserva de la Biosfera Cabo de Hornos. Anales del Instituto de la Patagonia, 48(3), 169-183.

Sarewitz, D. (2004). How science makes environmental controversies worse. 
Environmental Science \& Policy, 7(5), 385-403.

Schlatter, R., \& Riveros, G. (1997). Historia Natural del Archipiélago Diego Ramírez, Chile. Ser. Cient. INACH, 47, 87-112.

Schüttler, E., Cárcamo, J., \& Rozzi, R. (2008). Diet of the American mink Mustela vison and its potential impact on the native fauna of Navarino Island, Cape Horn Biosphere Reserve, Chile. Revista Chilena de Historia Natural, 81, 599-613.

Schüttler, E., Klenke, R., McGehee, S., Rozzi, R., \& Jax, K. (2009). Vulnerability of groundnesting waterbirds to predation by invasive American mink in the Cape Horn Biosphere Reserve, Chile. Biological Conservation, 142, 1450-1460.

Schüttler, E., Ibarra, T., Gruber, B., Rozzi, R., \& Jax, K. (2010). Abundance and habitat preferences of the southernmost population of mink: implications for managing a recent island invasion. Biodiversity and Conservation, 19, 725-743.

Schüttler, E., Rozzi, R., \& Jax, K. (2011). Towards a societal discourse on invasive species management: a case study of public perceptions of mink and beavers in Cape Horn. Journal for Nature Conservation, 19, 175-184.

Schüttler, E., Saavedra-Aracena, L., \& Jiménez, J. E. (2018). Domestic carnivore interactions with wildlife in the Cape Horn Biosphere Reserve, Chile: husbandry and perceptions of impact from a community perspective. PeerJ., 6, e4124. http://doi/10.7717/ peerj. 4124

Schüttler, E., Crego, R., Saavedra, L., Silva, E. A., Rozzi, R., Soto, N., \& Jiménez, J. E. (2019). New records of invasive mammals from the subAntarctic Cape Horn Archipelago. Polar Biology, 42, 1093-1105.

Scott, J. J., \& Kirkpatrick, J. B. (2008). Rabbits, landslips and vegetation change on the coastal slopes of subantarctic Macquarie Island, 1980-2007: implications for management. Polar Biology, 31(4), 409419.

Sepúlveda, M. A., Valenzuela, A. E. J., Pozzi, C., Medina-Vogel, G., \& Chehébar, C.
(2015). Lontra provocax. The IUCN Red List of Threatened Species 2015, e.T12305A21938042. http://dx.doi. org/10.2305/IUCN.UK.2015-2.RLTS. T12305A21938042.

Silva-Rodríguez, E. A., Acosta-Jamett, G., Villatoro, F., Stowhas, P., Ohrens, O., \& Naughton-Treves, L. (2018). Conflictos en el manejo de la fauna silvestre en Chile: daños causados por animales silvestres, conductas hacia la fauna y conflictos humano-humano. En C. Cerda, E. A. Silva-Rodríguez, \& C. Briceño (Eds.), Naturaleza en sociedad: una mirada a la dimensión humana de la conservación de la biodiversidad (pp. 241278). Santiago: Editorial Ocho Libros.

Simões, F. L., Contador-Mejias, T., Rendoll-Cárcamo, J., Pérez-Troncoso, C., Hayward, S. A., Turner, E., \& Convey, P. (2020). Distribution and Habitat Preferences of the Newly Rediscovered Telmatogeton magellanicus (Jacobs, 1900) (Diptera: Chironomidae) on Navarino Island, Chile. Insects 11: 442 doi:10.3390/insects11070442

Squeo, F. A., \& Méndez, F. A. (2019). Reserva de Biósfera Fray Jorge: más que un bosque relicto de neblina. En C. Smith-Ramírez, \& F. A. Squeo (Eds.), Biodiversidad y ecología de los bosques costeros de Chile (pp. 223237). Valdivia: Editorial Universidad de Los Lagos.

Steffen, W. L., Scholes, R. J., Valentin, C., Zhang, X., Menaut, J. C., \& Schulze, E. D. (1999). The IGBP terrestrial transects. In B. H. Walker, W. L. Steffen, J. G. Canadell, \& J. S. I. Ingram (Eds.), The terrestrial biosphere and global change: Implications for natural and managed ecosystems (pp. 66-87). Cambridge: Cambridge University Press.

Sundareshwar, P. V., Murtugudde, R., Srinivasan, G., Singh, S., Ramesh, K. J., Ramesh, R., Verma, S. B., Agarwal, D., Baldocchi, D., Baru, C. K., \& Baruah, K. K. (2007). Environmental monitoring network for India. Science, 316, 204-205.

Tuba, Z., Slack, N. G., \& Stark, L. R. (Eds.). (2011). Bryophyte ecology and climate change. Cambridge: Cambridge University Press. 
UNESCO. (1996). Reservas de biosfera: la estrategia de Sevilla y el marco estatutario de la red mundial. París: UNESCO.

UNESCO. (2016). Declaración de Lima relativa al Programa sobre el Hombre y la Biosfera (MAB) de la UNESCO y su Red Mundial de Reservas de Biosfera (RMRB). Consejo Internacional de Coordinación del Programa sobre el Hombre y la Biosfera (MAB) $28^{a}$ reunión Lima, Perú, marzo de 2016 http://rerb.oapn.es/images/ PDF_publicaciones/plan_de_accion_de_ lima-2016-2025.pdf [Consultado el 28 de marzo de 2017]

Universidad Nacional de La Plata. (2017). http://www.arquinstal.com.ar/atlas.html Consultado el 25 de marzo de 2017.
Valdenegro, A., \& Silva, N. (2003). Caracterización física y química de la zona de canales y fiordos australes del Estrecho de Magallanes y Cabo de Hornos (CIMAR 3 Fiordos). Ciencia y Tecnología Marina, 26, 19-60.

Valqui, J., \& Rheingantz, M. L. (2015). Lontra felina (errata version published in 2017). The IUCN Red List of Threatened Species 2015. e.T12303A117058682. http:// dx.doi.org/10.2305/IUCN.UK.2015-2. RLTS.T12303A21937779.en. Accessed 26 de Abril 2018.

Weathers, K. C., Lovett, G. M., Likens, G. E., \& Caraco, N. F. M. (2000). Cloudwater inputs of nitrogen to forest ecosystems in southern Chile: Forms, fluxes, and sources. Ecosystems, 3, 590-595. 